\section{A) Check for updates}

Cite this: Analyst, 2020, 145, 6691

\title{
Structural investigation of oxidized arabinoxylan oligosaccharides by negative ionization HILIC-qToF-MS $\dagger$
}

\begin{abstract}
Teresa Demuth, (D) Samy Boulos (D) and Laura Nyström*
Owing to the strong structure-function relationship of polysaccharides, the targeted modification of polysaccharides is attracting widespread interest in various fields, such as food industry, nutritional science, and biomedical research. Apart from intended functionalization, polysaccharide degradation mediated by hydroxyl radicals ( $\mathrm{HO}^{\circ}$ ) occurs in various industrial processes such as food processing. In particular, the oxidative degradation of feruloylated arabinoxylan (AX), a linearly-branched polysaccharide in cereals, causes chain scissions, and introduces new functional groups in the fiber, which can potentially modify the physicochemical properties and the functionalities of AX. However, the precise characterization of those structural modifications remains challenging due to the diversity of the oxidation products formed, the high molecular weight, and the relatively low quantity of newly formed functional groups. In this paper, selective (TEMPO-mediated) and random (Fenton) oxidations of several commercial xylo- and arabinoxylan oligosaccharides (A)XOS were studied as model systems by hydrophilic interaction UPLC-MS ${ }^{2}$ in negative ion resolution mode to identify potential oxidation products. An in-depth identification of acidic (A)XOS oxidation products derived from TEMPO-mediated oxidation provided novel insights in the selective functionalization of isomeric oligosaccharides. Furthermore, $\mathrm{MS}^{2}$ enabled the precise localisation of both glycosidic linkages and functional groups in oxidized (A)XOS. An innovative combination of an enzymatic sample preparation combined with a subsequent HILIC-MS ${ }^{2}$ analysis enabled the unprecedented comprehensive characterization of Fenton-induced oxidation products derived from AX. In future, this holistic analytical approach will enable the characterization of both selective and non-selective AX oxidation procedures in various applications.
\end{abstract}

Received 3rd June 2020, Accepted 6th August 2020

DOI: 10.1039/d0an01110j

rsc.li/analyst of polysaccharides unspecifically, leading to a significant alteration of their health promoting and technological functionalities. $^{3-5}$

One of the major non-digestible polysaccharides within the human diet is feruloylated arabinoxylan (AX), a partially soluble fiber predominantly found in the cell wall of cereal grains such as rye, wheat, barley, and oat. The polysaccharide is composed of a $\beta$ - $(1 \rightarrow 4)$-linked $\mathrm{D}$-xylopyranosyl backbone with random substitutions at O-2, O-3, or O-2 and O-3 with $\alpha-\mathrm{L}^{-}$ arabinofuranose units. Phenolic acids, primarily ferulic acid, can be esterified on the $\mathrm{C}(\mathrm{O})-5$ position of arabinose units. ${ }^{6}$ Since cereals usually undergo extensive processing treatments such as grain milling, extrusion, hydrothermal treatments, or baking, $\mathrm{AX}$ is prone to degradation induced by those processes. $^{5}$

This degradation process includes hydrolytic reactions and chemically-induced oxidations. Thereby, the chemicallyinduced oxidative degradation takes place by hydroxyl radials (HO') randomly abstracting hydrogen atoms from any $\mathrm{C}-\mathrm{H}$ groups within the monomer units, introducing new functional 
groups and causing - depending on the attack position within the monomers - also chain cleavage of the polymer backbone. $\mathrm{HO}^{\circ}$ can be generated through the Fenton reaction (1), mediating the oxidation of $\mathrm{AX} .^{7}$ All in all, a combination of molecular oxygen, metal traces (Fe, $\mathrm{Cu}$ ), and reducing agents build the catalytic cycle for $\mathrm{HO}^{\circ}$ production. ${ }^{8-10}$

$$
\mathrm{Fe}^{2+}+\mathrm{H}_{2} \mathrm{O}_{2}+\mathrm{H}^{+} \rightarrow \mathrm{Fe}^{3+}+\mathrm{H}_{2} \mathrm{O}+\mathrm{HO}^{\bullet}
$$

As a consequence, carbonyl or carboxyl groups are formed, ring openings occur, and the $M_{\mathrm{w}}$ decreases. ${ }^{8}$ Since such structural features (new functional groups \& chain length) are related to the solubility, viscosity and the derived functionalities of $\mathrm{AX}$, the identification of those structural changes is crucial to understand AX's nutritional value. ${ }^{11}$ However, the analysis of oxidized polysaccharide is challenging due to the high $M_{w}$ and the relatively small number of newly formed functional groups. Prior research has focused on the application of multiple analytical techniques studying the oxidative state of polysaccharides such as AX. In prior studies, Bagdi et al. and Faure et al. used electron spin resonance spectroscopy (ESR) to monitor the $\mathrm{HO}^{\circ}$ formation during polysaccharide oxidation. $^{7,12}$ In addition, Bagdi et al. studied the influence of AX oxidation on molecular weight, viscosity, bile acid binding, and gel forming capacity. Similar studies have also been performed with $\beta$-glucan, in which the main focus was the determination of bulk properties and rheology. ${ }^{13,14}$ A deeper insight into the molecular level of polysaccharide oxidation was presented by Potthast et al., who quantified carbonyls in polysaccharides through fluorescent labelling by high performance size exclusion chromatography (HPSEC) with multiple detectors. ${ }^{15}$ In a previous study, oligosaccharide products diagnostic for $\beta$-glucan oxidation were investigated by UPLC-MS ${ }^{2}$ with and without prior functional group labelling, followed by selective enzymatic digestion and solid phase extraction. ${ }^{16}$ Among the analytical approaches mentioned, liquid chromatography (LC) combined with mass spectrometry (MS), is one of the most powerful techniques to analyse oligosaccharides diagnostic for oxidation. ${ }^{17-19}$ However, to the best of our knowledge, there is no reported study using this technology for the characterization of Fenton oxidized arabinoxylan, and thus the structural building blocks of oxidized AX have yet to be elucidated. ${ }^{20,21}$

Hence, this study aims to elucidate the structural modification of diagnostic arabinoxylan oligosaccharides (A)XOS through selective TEMPO-mediated and non-selective Fenton oxidation in a holistic analytical approach and its subsequent application on non-selectively oxidized AX. For this purpose, a detailed characterization of oxidized (A)XOS as model compounds using hydrophilic interaction liquid chromatography (HILIC) coupled with $\mathrm{MS}^{2}$ in negative ion resolution mode was performed. Our work is the first application of this established method for branched heterooligosaccharides. An in-depth identification of acidic (A)XOS oxidation products derived from TEMPO-mediated oxidation provided insights in the selective functionalization of isomeric oligosaccharides. Moreover, this paper presents an unprecedented comprehen- sive characterization of the radical induced Fenton oxidation of (A)XOS. In a proof of concept experiment, the complex product mixture of Fenton-mediated arabinoxylan oxidation was characterized in detail using an innovative combination of an enzymatic sample preparation strategy and HILIC-MS ${ }^{2}$ analysis.

\section{Materials and methods}

\subsection{Materials}

Linear XOS (X3, X4, X5, and X6), branched AXOS standards $\left(\mathrm{A}^{3} \mathrm{X}, \mathrm{A}^{2} \mathrm{XX}, \mathrm{XA}^{3} \mathrm{XX}, \mathrm{A}^{2+3} \mathrm{XX}\right)$ both $>95 \%$, wheat arabinoxylan (medium viscosity; $\sim 95 \%$ ), and endo-1,4- $\beta$-xylanase from Cellvibrio mixtus (750 $\mathrm{U} \mathrm{mL}^{-1}$ ) were purchased from Megazyme International (Bray, Ireland), ammonium formate ( $\geq 99.995 \%$ trace metal basis), 25\% aqueous ammonia $\left(\mathrm{NH}_{3}\right)$ and formic acid (both LC-MS grade), 35\% hydrogen peroxide $\left(\mathrm{H}_{2} \mathrm{O}_{2}\right.$; purum p.a.), iodine ( $\mathrm{I}_{2} ; \geq 99.8 \%$ ), iron(II) sulfate heptahydrate $\left(\mathrm{FeSO}_{4} \cdot 7 \mathrm{H}_{2} \mathrm{O} ; \geq 99 \%\right.$ ), methanol (HPLC-grade), potassium hydroxide $(\mathrm{KOH} ; \geq 85 \%)$, sodium chlorite $\left(\mathrm{NaClO}_{2} ; 80 \%\right)$, sodium hydroxide $(\mathrm{NaOH} ; \geq 97.0 \%)$, sodium hypochlorite solution (NaClO; 10-15\%), and 2,2,6,6-tetramethylpiperidine 1-oxyl (TEMPO; 98\%) were purchased from Sigma-Aldrich Chemie GmbH (Germany). L-Ascorbic acid (AA; $\geq 99.5 \%$ ) was purchased from Fluka (Germany). Acetonitrile (ACN; ULC/MS grade) was purchased from Biosolve B.V. (Valkenswaard, The Netherlands) and the aqueous solutions were prepared with nanopure Milli$\mathrm{Q}{ }^{\circledR}$ water $\left(\mathrm{H}_{2} \mathrm{O} ; \geq 18.2 \mathrm{M} \Omega \mathrm{cm}\right.$ at $\left.25^{\circ} \mathrm{C}\right)$.

\subsection{Methods}

2.2.1. Synthesis of xylonic acid-bearing oligosaccharide standards by $\mathrm{I}_{2} / \mathrm{KOH}$. Xylonic acids of $\mathrm{A}^{3} \mathrm{X}, \mathrm{X} 3, \mathrm{~A}^{2} \mathrm{XX}, \mathrm{X} 4, \mathrm{~A}^{3} \mathrm{XX}$, $\mathrm{A}^{2+3} \mathrm{XX}, \mathrm{X} 5$, and $\mathrm{X} 6$ were synthesised by selective $\mathrm{C} 1$-oxidation of the native oligomers. The reducing end was oxidized with hypoiodite based on a procedure presented by Hashimoto et al. with modifications. ${ }^{22}$ The oligomers ( $2 \mu \mathrm{mol} ; 1$ equiv.) were dissolved in $\mathrm{H}_{2} \mathrm{O}(1.5 \mathrm{~mL})$ and sonicated for $5 \mathrm{~min}$. Afterwards, methanolic $\mathrm{I}_{2}$ solution $(0.1 \mathrm{M}, 60 \mu \mathrm{L} ; 3$ equiv.) was added, followed by aqueous $\mathrm{KOH}$ solution $(0.1 \mathrm{M}, 160 \mu \mathrm{L} ; 8$ equiv.). The final reaction volume was adjusted to $3 \mathrm{~mL}$ with $\mathrm{H}_{2} \mathrm{O}$, mixed, and fractionized by solid phase extraction after $1 \mathrm{~h}$ at room temperature (see section 2.2.4).

2.2.2. Acidic oxidation products of (A)XOS by TEMPOmediated oxidation. The preparation of acidic oxidation products was performed using the TEMPO/NaClO/ $\mathrm{NaClO}_{2}$ system. $^{23}$ (A)XOS (16 $\mu \mathrm{mol} ; 1$ equiv.) were dissolved in acetate buffer ( $\mathrm{pH}$ 4.7; $10 \mathrm{mM}, 1 \mathrm{~mL}$ ). Then, $\mathrm{NaClO}_{2}(29 \mathrm{mM}, 221 \mu \mathrm{L}$; 40 equiv.), TEMPO ( $2 \mathrm{mM}, 320 \mu \mathrm{L} ; 4$ equiv.), and $\mathrm{NaOCl}$ (13 mM, $615 \mu \mathrm{L} ; 50$ equiv.) were added. The final reaction volume was adjusted to $10 \mathrm{~mL} \mathrm{H}_{2} 0$, mixed and stirred for $24 \mathrm{~h}$ at $20{ }^{\circ} \mathrm{C}$. The reaction was stopped by SPE fractionation (see section 2.2.4).

\subsubsection{Fenton degradations}

2.2.3.1. (A)XOS. For the non-selective oxidation of (A)XOS, a reaction mixture of $1.5 \mathrm{~mL}$ final volume was prepared con- 
taining $1 \mathrm{mM}$ of the respective oligosaccharide, $100 \mu \mathrm{M} \mathrm{FeSO}_{4}$, $500 \mu \mathrm{M}$ ascorbic acid (AA), and $10 \mathrm{mM} \mathrm{H}_{2} \mathrm{O}_{2}$ on the basis of Bagdi et al. with some modifications. ${ }^{24}$ The oxidation was performed at room temperature $\left(22-24^{\circ} \mathrm{C}\right)$ with access to air for $24 \mathrm{~h}$. Each oxidation was done in triplicates, including reagent controls that contained only the oligosaccharide in water. SPE fractionation followed as usual (see section 2.2.4.).

2.2.3.2. AX polymer. Arabinoxylan (132 mg) was dissolved in $\mathrm{H}_{2} \mathrm{O}(5 \mathrm{~mL})$ for $1 \mathrm{~h}$ at $80^{\circ} \mathrm{C}$ and stirred at $20^{\circ} \mathrm{C}$ overnight. Subsequently, the reagents were added to give final concentrations of $2 \% \mathrm{AX}(\mathrm{w} / \mathrm{v}), 50 \mu \mathrm{M} \mathrm{FeSO}_{4}, 50 \mu \mathrm{M} \mathrm{AA}$, and $50 \mathrm{mM}$ $\mathrm{H}_{2} \mathrm{O}_{2}$ in this order. ${ }^{24}$ The oxidation was heated for the first 3 hours to $80^{\circ} \mathrm{C}$, then continued at RT with access to air for $24 \mathrm{~h}$. The oxidation was done in triplicates, including reagent controls, and subsequently freeze dried. The oxidized AX (15 mg) was dissolved in $\mathrm{H}_{2} \mathrm{O}(2.4 \mathrm{~mL})$ for $1 \mathrm{~h}$ at $80{ }^{\circ} \mathrm{C}$. Then, sodium phosphate buffer $(0.5 \mathrm{M}, 60 \mu \mathrm{L}, \mathrm{pH} 6.5)$ was added resulting in a final $\mathrm{AX}$ concentration of $0.5 \%(\mathrm{w} / \mathrm{v})$ and a total volume of $3 \mathrm{~mL}$. Subsequently, the oxidized $\mathrm{AX}$ was treated with endo-1,4- $\beta$-xylanase from Cellvibrio mixtus $\left(750 \mathrm{U} \mathrm{mL}^{-1}\right.$, $144 \mu \mathrm{L}$ ) for $6 \mathrm{~h}$ at $40{ }^{\circ} \mathrm{C}$ to decrease the molecular weight.

2.2.4. Solid phase extraction (SPE). The reducing end oxidized (A)XOS were fractionated using the procedure as previously reported. ${ }^{21}$ The supelclean ${ }^{\mathrm{TM}}$ ENVI-Carb SPE cartridges $(3.0 \mathrm{~mL}, 0.25 \mathrm{~g})$ from SUPELCO ${ }^{\circledR}$ (Sigma-Aldrich, Germany) were preconditioned with $3.0 \mathrm{~mL}$ ACN and $3.0 \mathrm{~mL} \mathrm{H}_{2} \mathrm{O}$. The reaction mixtures were loaded on the SPE cartridges and subsequently washed with $1.5 \mathrm{~mL} \mathrm{H}_{2} \mathrm{O}$ with a drop speed of 1-3 drops per second. The remaining native oligomers and neutral side products were eluted with $1.5 \mathrm{~mL} \mathrm{ACN} / \mathrm{H}_{2} \mathrm{O} 1: 3(\mathrm{v} / \mathrm{v})$ (fraction 1). Following, $1.5 \mathrm{~mL}$ of $0.1 \%(\mathrm{v} / \mathrm{v})$ formic acid in $\mathrm{ACN} /$ $\mathrm{H}_{2} \mathrm{O} 1: 3(\mathrm{v} / \mathrm{v})$ was used to elute fraction 2 containing the desired $\mathrm{C} 1$ oxidized product. Fractions 2 were collected directly in HPLC vials and analysed by UPLC-MS ${ }^{2}$.

\subsection{UPLC-MS and $M^{2}$}

2.3.1. Instrumentation. The Acquity UPLC system was equipped with an Acquity UPLC BEH Amide column $(2.1 \mathrm{~mm}$ $\times 150 \mathrm{~mm}, 1.7 \mu \mathrm{m})$. The UPLC was coupled to a Synapt G2 MS system with an electrospray ionisation (ESI) source and a quadrupole time-of-flight (qToF) analyser (Waters Corp., Milford, MA, USA). The calibration of the MS was done with sodium formate solution and leucine-enkephalin $(\mathrm{m} / \mathrm{z} 554.2615)$ was used as lock mass. This lock mass was acquired every $45 \mathrm{~s}$ during the measurements in negative ion mode (correction applied with 5 scans averaged).

2.3.2. Chromatographic conditions. Both gradients applied were based on ACN and $\mathrm{H}_{2} \mathrm{O}$ as eluents with a flow rate of $0.34 \mathrm{~mL} \mathrm{~min}{ }^{-1}$. Mixtures of $\mathrm{ACN} / \mathrm{H}_{2} \mathrm{O} 8: 2$ and $2: 8(\mathrm{v} / \mathrm{v})$ were used as weak and strong needle wash solutions, respectively. Injection volumes were $5 \mu \mathrm{L}-10 \mu \mathrm{L}$ of the undiluted and diluted sample $(75 \% \mathrm{ACN})$ in partial loop mode, respectively. The column was maintained at $35{ }^{\circ} \mathrm{C}$. The first gradient (Gradient I) for an overall analysis of the reaction mixture started with $20 \% \mathrm{H}_{2} \mathrm{O}$ and $80 \%$ ACN (both with $0.1 \% \mathrm{NH}_{3}$ additive), then increased linearly to $40 \% \mathrm{H}_{2} \mathrm{O}$ in $12 \mathrm{~min}$. After maintaining this for $4 \mathrm{~min}$, it was reequilibrated with the initial conditions for $1 \mathrm{~min}$.

The second gradient was applied for an improved separation of the acidic oxidation products (Gradient II) based on the procedure presented by Westereng et al. ${ }^{25}$ Eluent A and $\mathrm{B}$ were a mixture of $\mathrm{ACN} / \mathrm{H}_{2} \mathrm{O}$ in the ratio of $1: 3$ and $3: 1$, both with the addition of $60 \mathrm{mM}$ ammonium formate buffer $\left(\mathrm{NH}_{4} \mathrm{HCO}_{2} ; \mathrm{pH} 8\right)$. The gradient started isocratically with $100 \%$ B for $2 \min \left(=25 \% \mathrm{H}_{2} \mathrm{O}\right)$, increased linearly to $34 \% \mathrm{~A}$ for $5.5 \min \left(=42 \% \mathrm{H}_{2} \mathrm{O}\right)$, maintained for $1.5 \mathrm{~min}$, and decreased back to $0 \% \mathrm{~A}$ within $1 \mathrm{~min}$ and reequilibrated for $2.5 \mathrm{~min}$.

2.3.3. MS conditions. For both eluent systems, spectra were acquired in resolution mode and the voltages of capillary, sample cone, and extraction cone were set at 2000, 15, and $3 \mathrm{~V}$ for the $\mathrm{NH}_{3}$ eluent system, respectively; whereas higher voltages were applied for the buffered ammonium formate eluent (2000, 25, and $4 \mathrm{~V}$ ). The desolvation gas flow rate was $850 \mathrm{~L}$ $\mathrm{h}^{-1}$ at $350^{\circ} \mathrm{C}$, cone gas flow was $20 \mathrm{~L} \mathrm{~h}^{-1}$ and the source temperature $120{ }^{\circ} \mathrm{C}$. The full scans were acquired from $\mathrm{m} / \mathrm{z} 50$ to 1200 with a scan rate of $1 \mathrm{~Hz}$ in centroid mode. In addition, with a selection of exact masses, $\mathrm{MS}^{2}$ was performed through collision-induced dissociation (CID) with Argon as collision gas. For a narrow $\mathrm{m} / \mathrm{z}$ isolation width, low mass (LM) resolution was set to 15 , and the transfer collision energies were ramps ranging from 5-15 to 10-60 V depending on propensity for fragmentation. The data collected were processed in MassLynx software, version 4.1 (Waters Corp., Milford, MA, USA). Base peak ion chromatograms (BPI) were backgroundcorrected by substracting a blank injection, $\mathrm{m} / \mathrm{z}$ signals that could be clearly assigned to contaminations where excluded. Peak integration was done in extracted ion chromatograms (XIC) with $m / z$ of the analyte in question $\pm 0.05 \mathrm{Da}$.

2.3.4. Data processing. The data collected were processed using MassLynx software, version 4.1 (Waters Corp., Milford, MA, USA). BPI chromatograms and MS spectra were background-corrected by subtracting the signals of a blank from the respective measurement day. Retention time shifts were corrected by standard measurements of the native oligosaccharides and chromatograms displayed were smoothed $(3 \times)$.

\section{Results \& discussion}

\subsection{Identification of selectively oxidized (A)XOS}

3.1.1. UPLC-MS ${ }^{2}$ differentiation of isomeric xylonic acidbearing oligosaccharides. One of the main acidic products formed during Fenton-induced degradation of poly- and oligosaccharides are the result of lytic C1-oxidation, which for AX would correspond to xylonic acid-bearing oligosaccharides. ${ }^{20,21}$ In order to enable clear distinction of isomeric xylonic acid oxidation products, several commercially available (A)XOS were oxidized by means of selective reactions, namely $\mathrm{I}_{2} / \mathrm{KOH}$ and TEMPO/NaClO/NaClO ${ }_{2}$ and compared by $\mathrm{MS}^{2}$. According to literature, TEMPO/NaClO/ $\mathrm{NaClO}_{2}$ preferentially oxidizes primary alcohols and reducing ends in sugar molecules which leads 
among others to the formation of $\mathrm{C} 1$ oxidation products. ${ }^{26}$ Those C1 oxidation products were further confirmed by the selective reducing end $\mathrm{C} 1$ oxidation using $\mathrm{I}_{2} / \mathrm{KOH}$ (data not shown). In a first step, NaClO initializes the oxidation of nitroxyl radicals such as TEMPO to their corresponding oxoammonium salt, which further oxidizes the primary hydroxyl groups of the sugar units to aldehydes. In a subsequent reaction, $\mathrm{NaClO}_{2}$ oxidizes the resulting aldehydes to carboxylic acids, which regenerates $\mathrm{NaClO} .^{23,27}$ This general mechanism makes clear why the reducing end is readily oxidized as well as it is an aldehyde in the open-chain form, and hence easily oxidized by $\mathrm{NaClO}_{2}$ to xylonic acids.

The obtained $\mathrm{MS}^{2}$ spectra of the TEMPO-mediated oxidized oligosaccharides revealed mainly signals originating from the fragmentation starting from the oxidized downstream end, as shown in Fig. 1 on the example of oxidized pentopentaoses (for -tetraoses and -trioses, see Fig. S1 in the ESI $\dagger$ ). This observation is in accordance with negative ion ESI-MS ${ }^{2}$ data reported for native (A)XOS by Juvonen et al. ${ }^{17}$ While linear, native XOS exclusively fragment from the reducing end $(\mathrm{A}, \mathrm{B}, \mathrm{C}$ fragments according to the nomenclature of Domon and Costello), ${ }^{28}$ native AXOS also present fragments which can be assigned to $\mathrm{Y}$ fragments originating from the fragmentation starting at the non-reducing end. The $\mathrm{Y}$ type fragments are more pronounced in some xylonic acid-bearing oligosaccharides, which may be attributed to the high ionizability of the carboxylate group that is part of all $\mathrm{Y}$ fragments in these xylonic acid products.

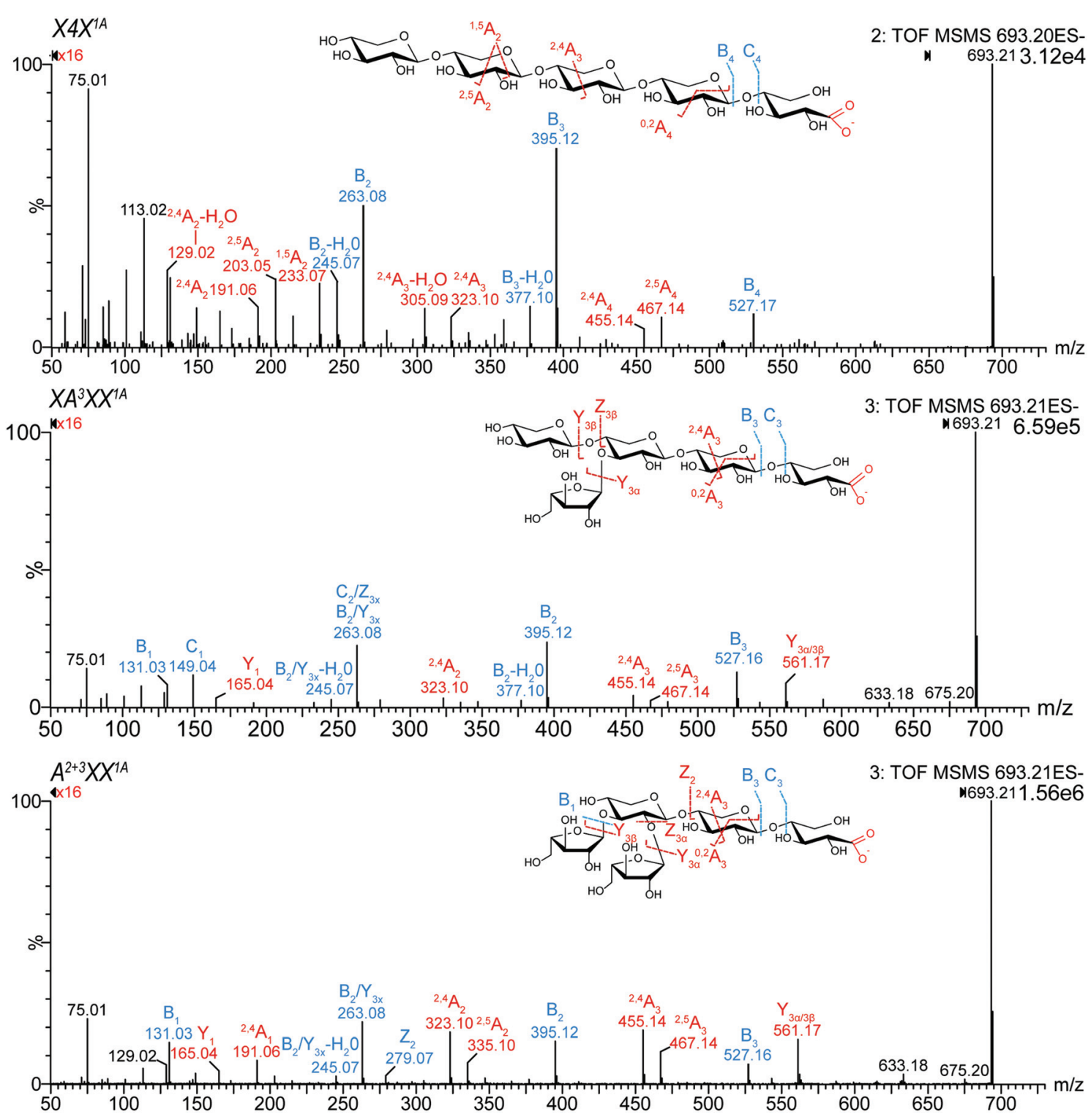

Fig. $1 \mathrm{MS}^{2}$ spectra of isomeric xylonic acid products with $\mathrm{m} / \mathrm{z}$ 693.21, obtained by TEMPO-mediated oxidation of pentopentaose standards. TEMPO/ $\mathrm{NaClO} / \mathrm{NaClO}_{2}$ preferentially oxidizes primary alcohols and reducing ends in sugar molecules, which leads among others to the formation of $\mathrm{C} 1$ oxidation products. ${ }^{26}$ Those $\mathrm{C} 1$ oxidation products were further confirmed by the selective $\mathrm{C} 1$ oxidation using $\mathrm{I}_{2} / \mathrm{KOH}$ (data not shown). The fragments were named according to the nomenclature of Domon and Costello. ${ }^{28}$ 
All studied isomeric pentose oligosaccharides (Pent $\left.{ }_{n}\right)$, namely $\mathrm{C} 1$-oxidized pentotrioses ( $\mathrm{X} 3$ and $\mathrm{A}^{3} \mathrm{X}$ ), pentotetraoses $\left(\mathrm{A}^{2} \mathrm{XX}\right.$ and $\left.\mathrm{X} 4\right)$, and pentopentaoses $\left(\mathrm{XA}^{3} \mathrm{XX}, \mathrm{A}^{2+3} \mathrm{XX}\right.$, and $\left.\mathrm{X} 5\right)$ could be clearly distinguished and linkage positions of arabinose substitution could be easily identified (see Fig. 1, Table 1, and Fig. S1†). Linear XOS xylonic acids $\left(\mathrm{Xyl}_{(n-1)} \mathrm{Xyl1A}=\mathrm{X}(n-\right.$ 1) $\mathrm{X}^{1 \mathrm{~A}}$ ) could be mainly elucidated by their dominating $\mathrm{B}$ fragments and the absence of $\mathrm{Y}_{(n-1)}$ fragment. In contrast, both mono- and disubstituted oligomers presented a $\mathrm{Y}_{(n-1)}$ fragment, presumably due to the ease of loss of a side chain arabinose unit. For AXOS, the ${ }^{1,5} \mathrm{~A}_{2}$ fragment ( $m / z$ 233.07) was less abundant compared to XOS. Moreover, particular linkages of the arabinose substitution could be identified by the signal ratios of ${ }^{2,4} \mathrm{~A}_{n} /{ }^{2,5} \mathrm{~A}_{n}$, namely $m / z$ 455.14/467.14 (for $n=5$ ), 323.10/335.10 (for $n \geq 4$ ), and 191.06/203.06 (for $n \geq 3$ ). While $m / z 467.14\left({ }^{2,5} \mathrm{~A}_{4}\right)$ was more abundant in oxidized linear X5 $\left(\mathrm{X}_{4} \mathrm{X}^{1 \mathrm{~A}}\right), \mathrm{m} / z 455.14\left({ }^{2,4} \mathrm{~A}_{4}\right)$ was dominating in both substituted pentopentaoses (ratio $>1$ ). Similar ratios of ${ }^{2,5} \mathrm{~A}_{2}$ (203.06) and ${ }^{2,4} A_{2}$ (191.06) were found for pentotrioses. The opposite could be observed for pentotetraoses, where ${ }^{2,4} \mathrm{~A}_{2}$ (323.10) was more abundant in oxidized linear $\mathrm{X} 4\left(\mathrm{X} 3 \mathrm{X}^{1 \mathrm{~A}}\right)$, and ${ }^{2,5} \mathrm{~A}_{3}$ (335.10) was dominating in $\mathrm{A}^{2} \mathrm{XX}^{1 \mathrm{~A}}$. Among the pentopentaoses evaluated, only the monosubstituted $\mathrm{XA}^{3} \mathrm{XX}^{1 \mathrm{~A}}$ formed $\mathrm{C}_{1}$ fragments $(\mathrm{m} / \mathrm{z}$

Table $1 \mathrm{MS}^{2}$ Overview of noteworthy diagnostic fragments (relative abundance $\geq 5 \%$ ) enabling the distinction of isomeric xylonic acid products. The fragments were named according to the nomenclature of Domon and Costello 28

\begin{tabular}{|c|c|c|}
\hline Oligosaccharide & Fragment ion $(\mathrm{m} / \mathrm{z})$ & $\begin{array}{l}\text { Missing fragment io } \\
(\mathrm{m} / \mathrm{z})\end{array}$ \\
\hline $\begin{array}{l}\text { Oxidized pentopentaoses } \\
\mathrm{X} 4 \mathrm{X}^{1 \mathrm{~A}}\end{array}$ & $\begin{array}{l}\text { Parent ion }(m / z 693.21) \\
{ }_{\mathbf{2 , 5}} \mathbf{A}_{\mathbf{3}}(335.10) \\
{ }_{\mathbf{1 , 5}} \mathbf{A}_{\mathbf{2}}(233.07) \\
{ }^{\mathbf{2 , 5}} \mathbf{A}_{\mathbf{2}}(203.05) \\
{ }^{\mathbf{2 , 4}} \mathbf{A}_{\mathbf{2}}(191.06) \\
\mathbf{C}_{\mathbf{1}}(\mathbf{1 4 9 . 0 4 )}\end{array}$ & $Y_{3 \boldsymbol{\alpha} / \boldsymbol{\beta}}(561.17)$ \\
\hline $\mathrm{XA}^{3} \mathrm{XX}^{1 \mathrm{~A}}$ & $\begin{array}{l}\mathbf{Y}_{3 \boldsymbol{\alpha} / \boldsymbol{\beta}}(561.17) \\
\mathbf{C}_{\mathbf{1}}(149.04)\end{array}$ & $\begin{array}{l}{ }^{2,5} \mathbf{A}_{\mathbf{3}}(467.14) \\
{ }^{2,4} \mathbf{A}_{\mathbf{3}}-\mathbf{H}_{\mathbf{2}} \mathbf{O}(305.09) \\
{ }^{2,5} \mathbf{A}_{\mathbf{2}}(335.10) \\
{ }^{2,5} \mathbf{A}_{\mathbf{2}}(203.05)\end{array}$ \\
\hline$A^{2+3} X^{1 A}$ & $\begin{array}{l}\mathbf{Y}_{3 \boldsymbol{\alpha} / \boldsymbol{\beta}}(561.17) \\
{ }^{\mathbf{2}, \mathbf{5}} \mathbf{A}_{\mathbf{2}}(335.10) \\
{ }^{\mathbf{2 , 4}} \mathbf{A}_{\mathbf{2}}(191.06)\end{array}$ & $\begin{array}{l}\mathbf{B}_{2}-\mathbf{H}_{2} \mathbf{O}(377.10) \\
{ }_{\mathbf{1 , 5}} \mathbf{A}_{\mathbf{2}}(233.07) \\
{ }^{2,5} \mathbf{A}_{\mathbf{2}}(203.05)\end{array}$ \\
\hline $\begin{array}{l}\text { Oxidized pentotetraoses } \\
\mathrm{X} 3 \mathrm{X}^{1 \mathrm{~A}}\end{array}$ & Parent ion $(m / z 561.17)$ & $\begin{array}{l}\mathbf{Y}_{3}(429.12) \\
\mathbf{Z}_{2}(279.07)\end{array}$ \\
\hline$A^{2} X X^{1 A}$ & $\begin{array}{l}\mathbf{Y}_{3}(429.12) \\
\mathbf{Z}_{2}(279.07) \\
\mathbf{Y}_{1}(165.04)\end{array}$ & \\
\hline Oxidized pentotrioses & Parent ion $(m / z 429.12)$ & \\
\hline $\mathrm{X} 2 \mathrm{X}^{1 \mathrm{~A}}$ & $\begin{array}{l}{ }^{\mathbf{1 , 5}} \mathbf{A}_{\mathbf{2}}(233.07) \\
{ }^{\mathbf{2} 5} \mathbf{A}_{\mathbf{2}}(203.06)\end{array}$ & $\mathbf{Y}_{2}(297.08)$ \\
\hline$A^{3} X^{1 A}$ & $\mathbf{Y}_{2}(297.08)$ & $\begin{array}{l}\mathbf{B}_{2}-\mathbf{H}_{2} \mathbf{O}(245.07) \\
{ }^{\mathbf{2}, 5} \mathbf{A}_{\mathbf{2}}(203.06) \\
{ }^{\mathbf{1 , 5}} \mathbf{A}_{\mathbf{2}}(233.07)\end{array}$ \\
\hline
\end{tabular}

149.04). Therefore, the region below $\mathrm{m} / \mathrm{z} 200$ allows for a facilitated differentiation of arabinose substitution pattern.

These findings are in line with the previously published $\mathrm{MS}^{2}$ differentiation of C1-oxidized gluco-oligosaccharides with gluconic acid downstream end. ${ }^{21}$ Consequently, all pentooligosaccharides with the same $\mathrm{m} / \mathrm{z}$ revealed unique $\mathrm{MS}^{2}$ fragmentation, which enables a clear identification of isomeric AX, (A)XOS derived oxidation products.

\subsubsection{Identification of acidic oxidation products of (A)XOS} from TEMPO-mediated oxidation. In the random oxidation e.g. during food processing, acidic products are one of the major oxidation product classes formed through lytic and non-lytic reactions. In this study, acidic products were synthetized by TEMPO-mediated oxidation and subsequently investigated by UPLC-MS ${ }^{2}$. The TEMPO/NaClO/ $/ \mathrm{NaClO}_{2}$ system converts primary hydroxyl groups in sugars to carboxylic acids.

Whereas linear XOS exclusively formed their corresponding xylonic acid product resulting from $\mathrm{C} 1$ xylose oxidation, AXOS created a mixture of acidic oxidation products resulting from both the $\mathrm{C} 1$ xylose oxidation and the $\mathrm{C} 5$ arabinose oxidation (see Fig. 2). Nevertheless, the product bearing the oxidized downstream end remained predominant during the AXOS oxidation as primary oxidation product. A variation of reagent equivalents corroborated the formation of reducing end oxidation prior to further oxidations at other positions (data not shown). ${ }^{21}$

Fig. 2 summarizes the successfully identified carboxylic acid-bearing oligosaccharides from $\mathrm{A}^{2+3} \mathrm{XX}$ and $\mathrm{A}^{2} \mathrm{XX}$ in the reaction mixture after TEMPO-mediated oxidation using $\mathrm{UPLC}_{\mathrm{MS}}{ }^{2}$ with a buffered ammonium formate eluent ( $\mathrm{pH} 8$ ). Generally, this gradient separated acidic products according to their size and polarity on the UPLC BEH Amide column. The specific products formed could be detected by their unique $\mathrm{m} / \mathrm{z}$ and even several isomeric products, e.g. of $\mathrm{m} / \mathrm{z} 559.15$, 575.15 , and 707.19 achieved appropriate separation by the gradient applied. In particular, $\mathrm{m} / \mathrm{z} 559.15$ can be assigned to a product after $\mathrm{C} 5$ oxidation in the arabinose unit as well as to a product after $\mathrm{C} 1$ and $\mathrm{C} 5$ oxidation of the downstream xylose unit.

\subsection{Identification of non-selective oxidized (A)XOS using Fenton oxidation}

3.2.1. Acidic products. The complex product mixture of Fenton oxidized oligosaccharides was characterized using HILIC-MS ${ }^{2}$. The general separation of acidic and neutral compounds could be achieved using a basic eluent system $(0.1 \%$ $\mathrm{NH}_{3}$ ). As already reported in a previous study as well as by Leijdekkers et al., this basic eluent caused nearly no retention and partial coelution of all acidic products on the amide HILIC column. ${ }^{21,29}$ However, their anionic natures lead to strong signal strength in the negative ion mode, which is shown as collective MS spectrum of the respective region in the chromatogram in Fig. $3 \mathrm{D}-\mathrm{F}$ for $\mathrm{A}^{2+3} \mathrm{XX}, \mathrm{XA}^{3} \mathrm{XX}$ and $\mathrm{X} 5$ as substrates. In contrast to direct infusion $\mathrm{MS}$, the data assembled already separated between neutral and charged products without a time-consuming sample preparation. 
(A) TEMPO-mediated oxidation products of $A^{2+3} X X$
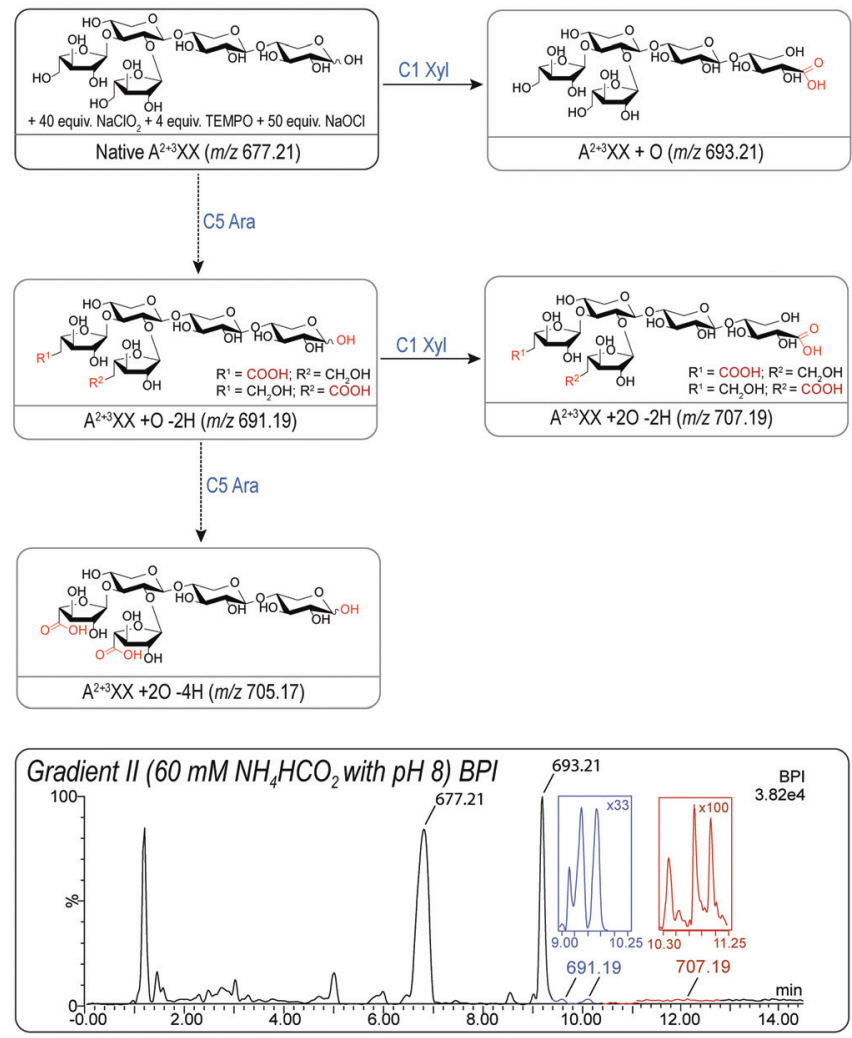

Fig. 2 Exemplary overview of TEMPO-mediated oxidation products of $A^{2+3} X X$ and $A^{2} X X$. The shown $m / z$ in parenthesis represent the deprotonated species $\left[\mathrm{M}-\mathrm{H}^{-}\right.$. The samples were analyzed by UPLC-MS using a buffered $60 \mathrm{mM}$ ammonium formate eluent system at pH 8 and a $\mathrm{BEH}$ Amide column. Several isomeric products were detected for $\mathrm{m} / \mathrm{z} 559.15,575.15$, and 707.19 differing in their oxidation position, e.g. $\mathrm{m} / \mathrm{z} 559.15 \mathrm{can}$ be assigned to a product after $\mathrm{C} 5$ oxidation in the arabinose unit as well as to a product after $\mathrm{C} 1$ and $\mathrm{C} 5$ oxidation of the downstream xylose unit. (A) TEMPO-mediated oxidation products of $A^{2+3} X X$. (B) TEMPO-mediated oxidation products of $A^{2} X X$.

The MS spectra from the oxidation of isomeric pentopentaoses (with $m / z$ 677.21) revealed signals clustered around the primary C1-oxidation products with $\mathrm{m} / \mathrm{z}$ 165.04, 297.08, 429.12, 561.17, and $m / z$ 693.21, representing Pent $(n-1)$ Xyl1A with $n=1$, $2,3,4$, and 5, respectively. Signals with the same number of monosaccharide units $n$, but higher $m / z$ than their respective pentose (Pent) acid oligomers, such as $m / z 707.19(n=5)$, are attributed to products with at least 1 additional oxygen, whereas products with lower $\mathrm{m} / \mathrm{z}$ refer tetrose-, glyceric-, and glyconic acid oligomers formed by cross-ring cleavages during Fenton oxidation.

As expected, all products formed and identified in the TEMPO-mediated oxidation of oligomers were also present in the complex product mixture of Fenton oxidized XOS and AXOS and were therefore easily identified (see Fig. 3D-F). Furthermore, the product distribution with respect to the degree of polymerization (DP) varies between the oligosaccharides analyzed (see Fig. 3 for $\mathrm{A}^{2+3} \mathrm{XX}, \mathrm{XA}^{3} \mathrm{XX}$, and $\mathrm{X} 5$ ). This observation shows that the fine structure influences the chain scission and oxidation behaviour of oligosaccharides, which is in contrast to previous findings on $\beta$-glucan oligomer oxidation, where similar results for all four linear glucotetratose

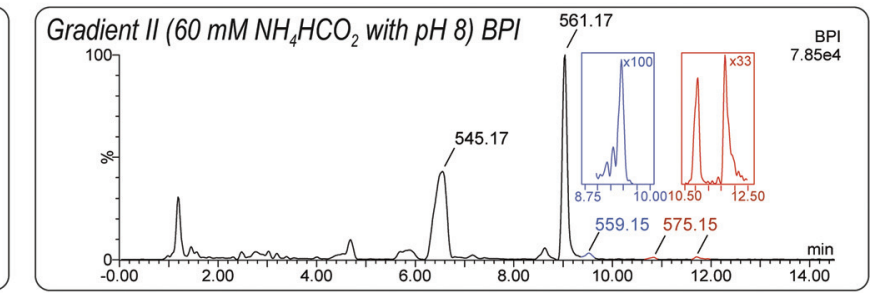

\section{(B) TEMPO-mediated oxidation products of $A^{2} X X$}
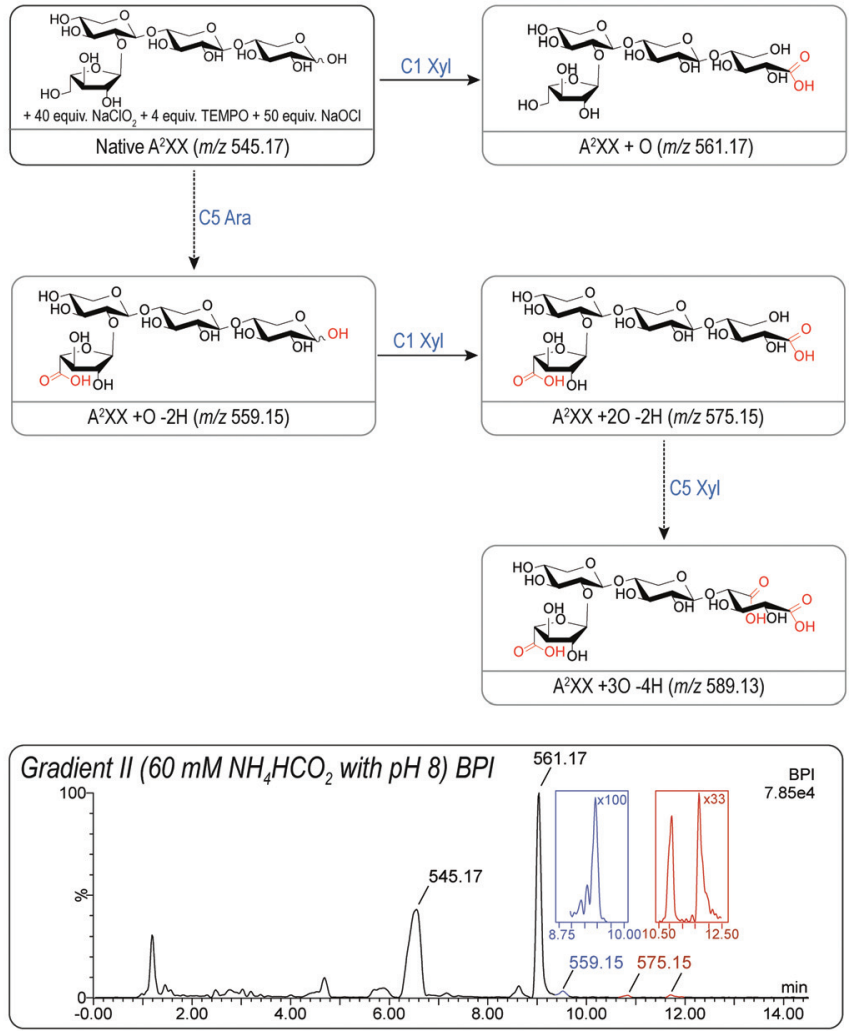

isomers could be observed. ${ }^{21}$ The product profile obtained from the Fenton oxidation of arabinoxylan will strongly depend on the native fine structure of the polysaccharide.

3.2.2. Neutral products. Neutral degradation products formed during Fenton oxidation were reduced in size and eluted before the native oligosaccharide. In general, the neutral product profiles of the constitutionally isomeric substrates, namely $\mathrm{X} 5, \mathrm{XA}^{3} \mathrm{XX}$, and $\mathrm{A}^{2+3} \mathrm{XX}$ differed greatly and a clear differentiation of isomeric degradation products was possible by their retention time (see Fig. $3 \mathrm{~A}-\mathrm{C}$ for $\mathrm{A}^{2+3} \mathrm{XX}$, $\mathrm{XA}^{3} \mathrm{XX}, \mathrm{X} 5$ ). Linear XOS eluted in order of their size (DP), but slightly later than the respective substituted AXOS isomer (see Fig. 3, and Fig. S2 $\dagger$ ). The most abundant products of the neutral fraction were oligosaccharides with reduced DP from lytic oxidation $\left(\mathrm{m} / z 545.17=\right.$ Pent $_{4}, \mathrm{~m} / z 413.13=$ Pent $\left._{3}\right)$ and their respective oxidized compounds with an additional carbonyl function (oxo-Pent ${ }_{n}$ of $m / z$ 675.20, 543.16, and 411.11 for $n$ $=5,4$, and 3 , respectively). The identified neutral products with reduced DP revealed cleavage reactions occurring from both the non-reducing or the downstream end, as well as loss of arabinose side chains. These oxo-products eluted both earlier and later than their respective native oligomers. 
(A) Gradient I (0.1\% $\left.\mathrm{NH}_{3}\right)$ BPI at $24 \mathrm{~h}$ Fenton Oxidation of $A^{2+3} \mathrm{XX}$
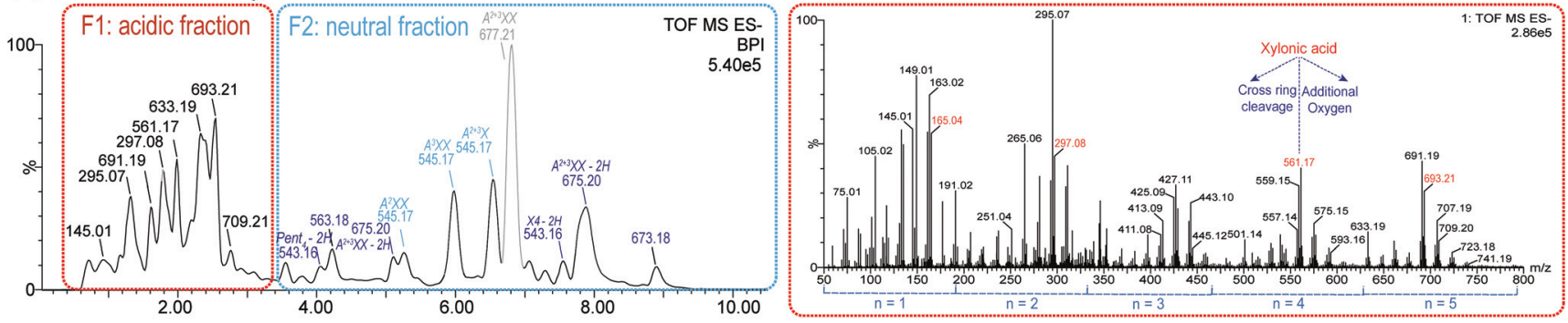

(B) Gradient I $\left(0.1 \% \mathrm{NH}_{3}\right) \mathrm{BPI}$ at $24 \mathrm{~h}$ Fenton Oxidation of $X A^{3} \mathrm{XX}$

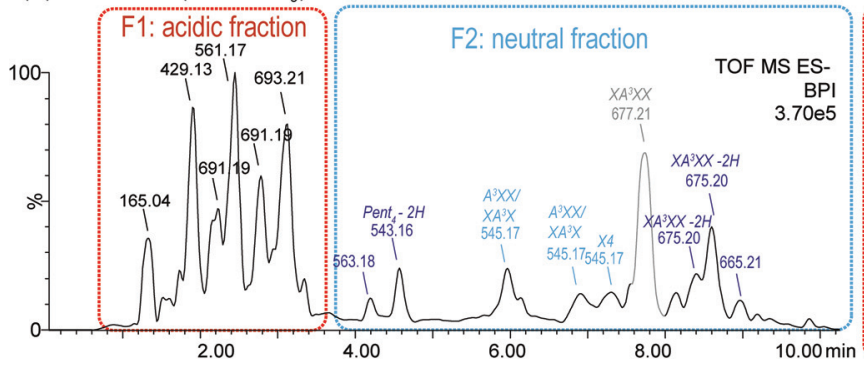

(E) F1: MS acidic fraction 1 of $X A^{3} X X$

(C) Gradient I $\left(0.1 \% \mathrm{NH}_{3}\right)$ BPI at $24 \mathrm{~h}$ Fenton Oxidation of $\mathrm{X} 5$
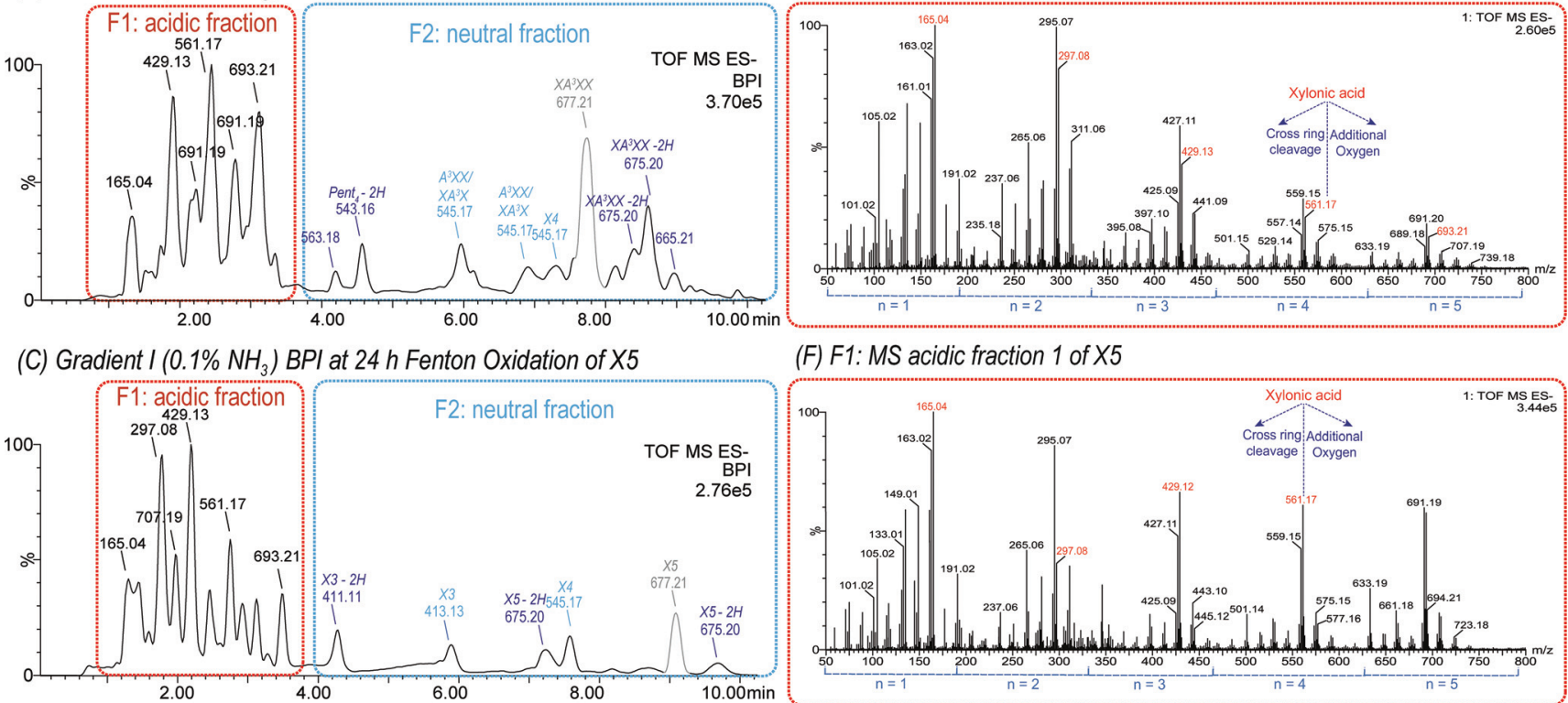

(F) F1: MS acidic fraction 1 of $X 5$

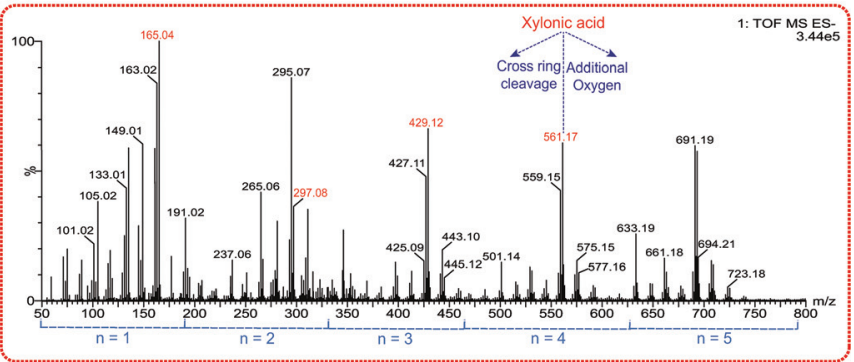

Fig. 3 UPLC-MS base peak ion chromatogram (BPI) using a $\mathrm{BEH}$ Amide column ( $\mathrm{ACN} / \mathrm{H}_{2} \mathrm{O}$ gradient I with $\mathrm{NH}$ additive) and negative ion mode ESI of $1 \mathrm{mM} \mathrm{A}^{2+3} \mathrm{XX}(\mathrm{A}), \mathrm{XA}^{3} \mathrm{XX}(\mathrm{B})$, and X5 (C) solution oxidized with $100 \mu \mathrm{M} \mathrm{FeSO}_{4}, 100 \mu \mathrm{M}$ ascorbic acid and $500 \mathrm{mM} \mathrm{H}_{2} \mathrm{O}_{2}$ after $24 \mathrm{~h}$ at room temperature. Peak area of the starting material is indicated in grey. ESI-MS spectra of acidic fraction (F1) of the respective oligosaccharides (D-F), derived from the red marked area in (A-C). Product assignment was based on elution time of native, commercial oligosaccharides (see Fig. S2 $\dagger$ ).

Presumably, this depends on the additional carbonyl position. Similar neutral product types as the one identified by Fenton oxidized (A)XOS, have been determined in the Fenton induced oxidation of arabinotriose by Moreira et al. and of $\beta$-glucan oligosaccharides as previously reported by Boulos and Nyström. ${ }^{16,20,21}$ Consequently, the basic gradient applied enables a facilitated detection of oxidation product with distinct differentiation of neutral constitutionally isomeric products.

3.2.3. Summary of detected products of oxidized (A)XOS using negative ion MS. Table 2 summarizes the detected and assigned Fenton oxidation products of $\mathrm{A}^{2+3} \mathrm{XX}$, as example, in both gradients using negative ion MS in resolution mode. In contrast to the basic gradient I, where both neutral and acidic products achieved appropriate signal strength, the buffered gradient revealed lower sensitivity due to ion suppression by $\mathrm{NH}_{4} \mathrm{HCO}_{2}$. However, isobaric oligosaccharides bearing carboxyl groups on different positions could be exclusively identified in the extracted ion chromatograms using the buffered eluent. In contrast to the previously reported method in which high resolution was required, the differentiation of near isobaric products with a mass difference of $\Delta m \geq 0.03 \mathrm{Da}\left(\right.$ e.g. $\mathrm{Xyl}_{3}{ }^{-}$ $\mathrm{CH}_{2} \mathrm{O}+2 \mathrm{O}-2 \mathrm{H}$ with $\mathrm{m} / z 413.09$ vs. $\mathrm{Xyl}_{3}$ with $\mathrm{m} / z$ 413.13) was achieved already by the more sensitive resolution $\mathrm{MS}^{21}$ As anticipated, the studied (A)XOS oxidation revealed a greater product variety, because of their numerous chain cleavage options. The majority of product types identified in this study are in accordance with products observed during hydroxyl radical-induced oxidation of arabinotriose, amylose, and amylopectin. ${ }^{20,30}$

The assembled data suggest that resolution HILIC-MS ${ }^{2}$ is a powerful technique for the rapid and precise structural identification of neutral and acidic oligomers derived from polysaccharide oxidation. Nevertheless, to characterize the complete product profile of hydroxyl radical-induced degradation, both gradients presented in this paper need to be applied. The basic gradient I enables the investigation of neutral oxidation products in combination with an MS scan of acidic products, whereas the buffered gradient II enables a distinct identification of acidic products and their structural variations. 
Table 2 Fenton-induced oxidation products of $A^{2+3} X X$ identified by negative ion UPLC-MS in resolution mode as [M - H] $]^{-}$after $24 \mathrm{~h}$ oxidation. A BEH Amide column was used in combination with both gradient systems $\left(\mathrm{ACN} / \mathrm{H}_{2} \mathrm{O}\right.$ gradient I with $\mathrm{NH}_{3}$ additive and gradient II with buffered $60 \mathrm{mM}$ ammonium formate eluent system at $\mathrm{pH} 8)^{a}$

\begin{tabular}{|c|c|c|c|c|c|}
\hline$n^{b}$ & 5 & 4 & 3 & 2 & 1 \\
\hline \multicolumn{6}{|l|}{ Neutral products } \\
\hline Pentose $_{n}\left(\right.$ Pent $\left._{n}\right)$ & $677.21^{d_{*}}$ & $545.17^{*}$ & $413.13^{*}$ & $281.09^{*}$ & 149.05 \\
\hline Pent $_{n}-2 \mathrm{H}$ & $675.20^{*}$ & $543.16^{*}$ & $411.11^{*}$ & $279.07^{*}$ & 147.03 \\
\hline Pent $_{n}-\mathrm{CH}_{2} \mathrm{O}$ & 647.19 & 515.15 & & & \\
\hline Pent $_{n}-\mathrm{CH}_{2} \mathrm{O}-2 \mathrm{H}$ & 645.18 & 513.14 & & & 117.02 \\
\hline Pent $_{n}-\mathrm{C}_{2} \mathrm{H}_{4} \mathrm{O}_{2}$ & & 485.15 & & & 89.03 \\
\hline Pent $_{n}-\mathrm{C}_{2} \mathrm{H}_{4} \mathrm{O}_{2}-2 \mathrm{H}$ & & & & & 87.01 \\
\hline \multicolumn{6}{|c|}{ Acidic products } \\
\hline \multicolumn{6}{|c|}{ Pentose acid series: xylonic, xylaric, and arabinuronic acid ${ }^{c}$} \\
\hline Pent $_{n}+\mathrm{O}$ & $693.20^{*}$ & $561.16^{*}$ & $429.13^{*}$ & $297.08^{*}$ & 165.04 \\
\hline Pent $_{n}+\mathrm{O}-2 \mathrm{H}$ & $691.19^{*}$ & $559.15^{*}$ & $427.12^{*}$ & $295.07^{*}$ & 163.03 \\
\hline Pent $_{n}+\mathrm{O}-4 \mathrm{H}$ & 689.17 & 557.13 & 425.09 & 293.05 & 161.01 \\
\hline Pent $_{n}+2 \mathrm{O}$ & 709.20 & $577.16^{*}$ & 445.12 & & \\
\hline Pent $_{n}+2 \mathrm{O}-2 \mathrm{H}$ & $707.18^{*}$ & $575.14 *$ & $443.10^{*}$ & $311.06^{*}$ & \\
\hline Pent $_{n}+2 \mathrm{O}-4 \mathrm{H}$ & & 573.13 & 441.09 & 309.05 & \\
\hline Pent $_{n}+3 \mathrm{O}-2 \mathrm{H}$ & 723.18 & 591.14 & 459.10 & 327.06 & \\
\hline Pent $_{n}+3 \mathrm{O}-4 \mathrm{H}$ & & & & 325.04 & \\
\hline \multicolumn{6}{|c|}{ Tetrose acid series: onic, uronic, and aric acids } \\
\hline Pent $_{n}-\mathrm{CH}_{2} \mathrm{O}+\mathrm{O}$ & 663.19 & 531.15 & 399.11 & 267.07 & 135.03 \\
\hline $\begin{array}{l}\mathrm{Pent}_{n}-\mathrm{CH}_{2} \mathrm{O}+\mathrm{O}- \\
2 \mathrm{H}\end{array}$ & 661.18 & 529.14 & 397.10 & 265.06 & 133.02 \\
\hline $\begin{array}{l}\mathrm{Pent}_{n}-\mathrm{CH}_{2} \mathrm{O}+\mathrm{O}- \\
4 \mathrm{H}\end{array}$ & & & & 263.04 & \\
\hline $\begin{array}{l}\mathrm{Pent}_{n}-\mathrm{CH}_{2} \mathrm{O}+2 \mathrm{O}- \\
2 \mathrm{H}\end{array}$ & 677.17 & 545.13 & 413.09 & 281.05 & 149.01 \\
\hline $\begin{array}{l}\mathrm{Pent}_{n}-\mathrm{CH}_{2} \mathrm{O}+2 \mathrm{O}- \\
4 \mathrm{H}\end{array}$ & & & 411.08 & 279.04 & \\
\hline \multicolumn{6}{|l|}{ Glyceric acid series } \\
\hline Pent $_{n}-\mathrm{C}_{2} \mathrm{H}_{4} \mathrm{O}_{2}+\mathrm{O}$ & 633.18 & 501.14 & 369.10 & 237.06 & 105.20 \\
\hline Pent $_{n}-\mathrm{C}_{2} \mathrm{H}_{4} \mathrm{O}_{2}+2 \mathrm{O}$ & 649.18 & & & & \\
\hline $\begin{array}{l}\mathrm{Pent}_{n}-\mathrm{C}_{2} \mathrm{H}_{4} \mathrm{O}_{2}+ \\
2 \mathrm{O}-2 \mathrm{H}\end{array}$ & 647.16 & 515.12 & & & \\
\hline $\begin{array}{l}\text { Pent }_{n}-\mathrm{C}_{2} \mathrm{H}_{4} \mathrm{O}_{2}+ \\
3 \mathrm{O}-2 \mathrm{H}\end{array}$ & & & & 267.04 & \\
\hline $\begin{array}{l}\text { Pent }_{n}-\mathrm{C}_{2} \mathrm{H}_{4} \mathrm{O}_{2}+ \\
3 \mathrm{O}-4 \mathrm{H}\end{array}$ & 661.14 & & & & \\
\hline \multicolumn{6}{|l|}{ Glyconic acid series } \\
\hline Pent $_{n}-\mathrm{C}_{3} \mathrm{H}_{6} \mathrm{O}_{3}+\mathrm{O}$ & & & & & 75.01 \\
\hline $\begin{array}{l}\mathrm{Pent}_{n}-\mathrm{C}_{3} \mathrm{H}_{6} \mathrm{O}_{3}+ \\
2 \mathrm{O}-2 \mathrm{H}\end{array}$ & & & 353.09 & & 89.01 \\
\hline \multicolumn{6}{|l|}{ Formic acid series } \\
\hline $\mathrm{Pent}_{n}-\mathrm{C}_{4} \mathrm{H}_{8} \mathrm{O}_{4}+\mathrm{O}-$ & & & 323.06 & & \\
\hline
\end{tabular}

${ }^{a}$ Experimental values of $m / z$ (all within $\pm 2 \mathrm{mDa}$ of theoretical values) with distinct peaks or $\geq 5 \%$ intensity relative to the base peak of the respective fraction (neutral: $\mathrm{m} / \mathrm{z}$ 663.199; acidic: $\mathrm{m} / \mathrm{z} 193.035$ ). An asterisk denotes products with $\geq 20 \%$ relative signal intensity. ${ }^{b}$ Indicates the number of total sugar units. ${ }^{c}$ The names of the monosaccharides are given according to the oxidized unit of the oligosaccharides. ${ }^{d}$ Starting material.

3.2.4. Differentiation of isomeric lytic pentose acid products by $\mathbf{M S}^{2}$. The identification of carbonyl groups (apart from $\mathrm{C} 1$ at the reducing end) is crucial, since they are a clear indicator of polysaccharide oxidation. Thereby, the $\mathrm{C}=\mathrm{O}$ location can indicate if it was formed via a lytic or a non-lytic process. In this study, $\mathrm{MS}^{2}$ analysis revealed interesting details about the location of carbonyl groups in the different evaluated oligosaccharides. As an example, the oxidation product $\mathrm{m} / \mathrm{z} 559.15$ can be attributed to deprotonated $\mathrm{Pent}_{4}+\mathrm{O}-2 \mathrm{H}$, and was found in Fenton oxidized X5 and $\mathrm{A}^{2+3} \mathrm{XX}$ under loss of one pentose unit (for fragmentation pattern, see Fig. 4). Generally, the product contains either

(i) one uronic acid group (from oxidation of one of the pentose units at $\mathrm{C} 5$, hence $-\mathrm{CH}_{2} \mathrm{OH} \rightarrow-\mathrm{COOH}$ ), which is then already fully responsible for $+\mathrm{O}-2 \mathrm{H}$; or

(ii) one carboxylic acid at the downstream end's C1 (forming xylonic acid, hence $-\mathrm{CHO} \rightarrow-\mathrm{COOH}$ ), plus an additional carbonyl group to account for the $-2 \mathrm{H}$. Due to the indiscriminate nature of $\mathrm{HO}^{\circ}$, various isomeric products would be expected for this option depending on the order of oxidation, and whether C1-oxidation or carbonyl formation was responsible for the chain scission.

Based on the acidic nature of the possible products, a clear separation of isomeric products could not be achieved by the basic gradient I. However, gradient II impeded acceptable $\mathrm{MS}^{2}$ spectra due to extensive ion suppression caused by the eluent buffer. Only gradient I allowed for sufficient signal abundance for collision induced fragmentation analysis. Consequently, the $\mathrm{MS}^{2}$ pattern of $m / z 559.15$ from both starting materials X5 and $\mathrm{A}^{2+3} \mathrm{XX}$ may represent a mixture of isomeric products. However, the fragments found allow for differentiation and identification of formed products. As shown for X5 oxidation, the pattern of $Y_{n}$ fragments $(\mathrm{m} / \mathrm{z} 429.12,297.08$, and 165.04 for $n=3,2$, and 1) produced through the loss of sugar units from the non-reducing end indicated the presence of a carboxylic acid group at the downstream end sugar unit, namely as a xylonic acid (Xyl1A) from C1 oxidation. In addition, these fragments corresponding to $\mathrm{Xyl}_{(n-1)} \mathrm{Xyl1A}(n=1-3)$ clearly showed that the additional carbonyl group is not located on the downstream end xylonic acid unit for this product. The neutral loss of -130 Da from the parent ion to the $\mathrm{Y}_{3}$ fragment $(\mathrm{m} / z 559.15$ $\rightarrow$ 429.12) corresponds to an eliminated ${ }^{\text {oxo } X y l ~ u n i t, ~ w h i c h ~}$ indicates a product with a carbonyl group at the non-reducing end. Furthermore, the fragment $\mathrm{m} / \mathrm{z} 129.02$ can be assigned to the mentioned ${ }^{{ }^{0 x} \mathrm{Xyl}}$ as $\mathrm{B}_{1}$ fragment itself.

There is some indication that the alternative possibility (i), namely a xyluronic acid-bearing oligosaccharide $\mathrm{Xyl}_{3} \mathrm{XylA}$, is at least a minor part of the product mixture for X5 oxidation: most notably, the fragment ion $m / z 409$, which could correspond to $\mathrm{Z}_{3}$ of $\mathrm{Xyl}_{3} \mathrm{XylA}$ (namely $\mathrm{Xyl}_{2} \mathrm{XylA}-\mathrm{H}_{2} \mathrm{O}$ ). And some fragments that could also be from ${ }^{{ }^{0 x o}} \mathrm{XylXyl}_{2} \mathrm{Xyl} 1 \mathrm{~A}$, but then need two collision induced scission events to explain them, vs. only one if originating from $\mathrm{Xyl}_{3} \mathrm{XylA}: \mathrm{m} / \mathrm{z} 263$ being $\mathrm{B}_{2}$ for the latter, and $\mathrm{B}_{3} / \mathrm{Y}_{3}$ for the former, as well as its dehydrated product $m / z 245$. Possibly, these fragments have contributions from both product isomers.

In the case of $\mathrm{A}^{2+3} \mathrm{XX}$ oxidation, the respective product with carbonyl at the non-reducing and C1-oxidized reducing end as found for X5 could be identified due to the occurrence of analogous fragment ions. However, additionally, the $\mathrm{MS}^{2}$ spec- 
(A) Fenton oxidation product of $X 5$ with $\mathrm{m} / \mathrm{z} 559.15$

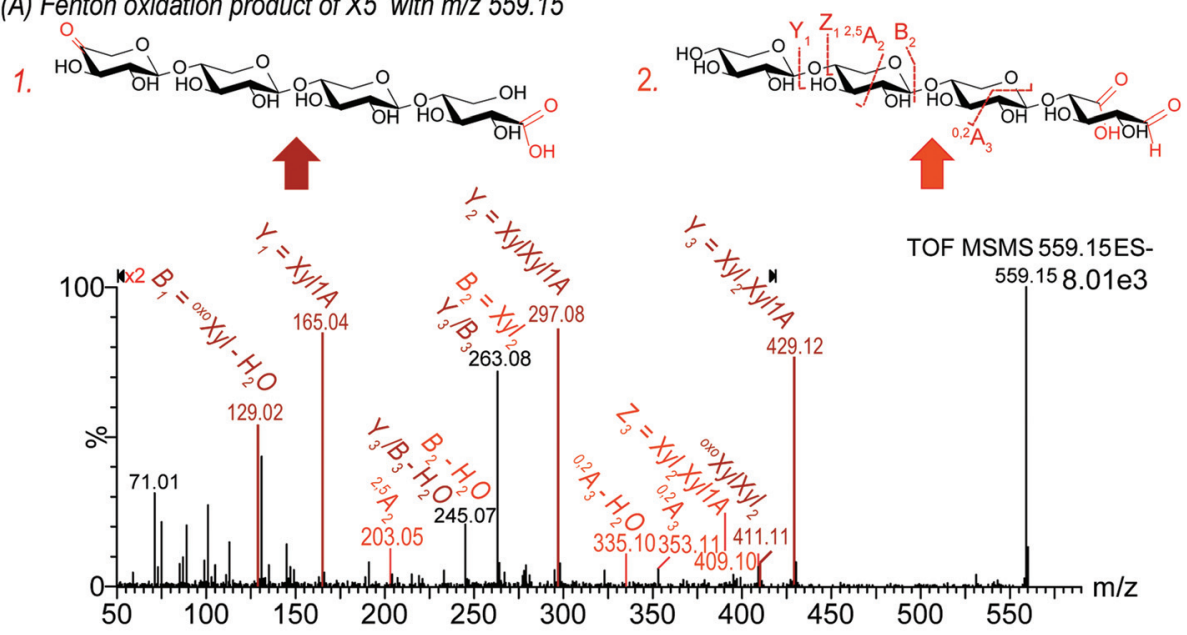

(B) Fenton oxidation product of $A^{2+3} X$ with $\mathrm{m} / \mathrm{z} 559.15$

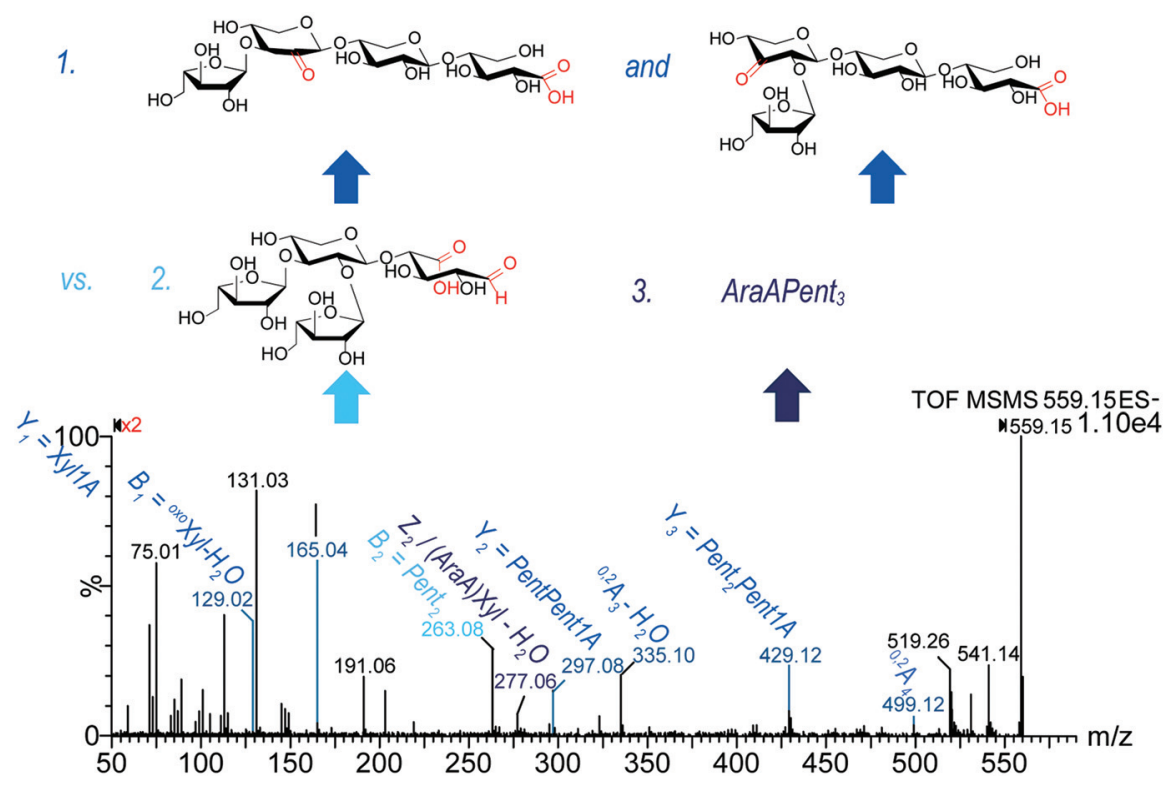

Fig. $4 \mathrm{MS}^{2}$ spectra of the oxidation product Pent $4+\mathrm{O}-2 \mathrm{H}$ with $\mathrm{m} / \mathrm{z} 559.15$, found for Fenton oxidized (A) X5 and (B) $\mathrm{A}^{2+3} \mathrm{XX}$ to determine the location of carbonyl and carboxylic acid groups. Fragments highlighted in color are identifying the structural unit indicated with an arrow of the same color.

trum contained fragment $m / z$ 277.06, which could be assigned to an arabinose unit bearing a carboxylic acid group at C5 (arabinuronic acid, AraA). Hence, for the Fenton-induced oxidation of both $\mathrm{X} 5$ and $\mathrm{A}^{2+3} \mathrm{XX}, \mathrm{m} / \mathrm{z} 559.15$ likely represents a mixture of ${ }^{\text {oxo }} \mathrm{Xyl}(\text { Pent })_{2} \mathrm{Xyl} 1 \mathrm{~A}$, and Pent ${ }_{3} \mathrm{XylA}$ from lytic C5 oxidation at the unit next to the reducing end, whereas for $\mathrm{A}^{2+3} \mathrm{XX}$, some C5 oxidized arabinose products (AraA)Pent ${ }_{3}$ is additionally present. Thus, $\mathrm{MS}^{2}$ analysis is a powerful technique to determine the oxidation site on the oligomers.

Regarding reaction pathways, having the carbonyl group only at the non-reducing end strongly suggests that its formation is part of the lytic step, namely, on the example of X5 oxidation, C4-oxidation with scission of the last $\beta-(1 \rightarrow 4)$ linkage, leading to ${ }^{4{ }^{0 x o}} \mathrm{XylXyl}_{3}$ (see Fig. 5). Introducing a carbonyl group is, in contrast to $\mathrm{C} 1$ oxidation, not selective - unless it is formed through lytic action, then it must be localized at the former glycosidic linkage position, which is $\mathrm{C} 4$ for the xylan backbone, and $\mathrm{C} 2$ or $\mathrm{C} 3$ in the case of Ara sidechains. Under $\mathrm{H}_{2} \mathrm{O}_{2}$ conditions, it is known that reducing ends oxidize relatively easily to the corresponding onic acid species. ${ }^{21}$ This is in accordance with earlier studies, where $\mathrm{MS}^{2}$ analysis was also used to localize the oxidation at the reducing or non-reducing end of glucose oligomers. ${ }^{16,21}$

\subsection{Characterization of the complex product mixture from Fenton oxidized AX polymer}

Wheat arabinoxylan (AX) was oxidized by Fenton-induced oxidation using $100 \mu \mathrm{M} \mathrm{FeSO}, 500 \mu \mathrm{M}$ ascorbic acid (AA), and $500 \mathrm{mM} \mathrm{H} \mathrm{H}_{2} \mathrm{O}_{2}$. Subsequently, (A)XOS were produced by endo1,4- $\beta$-xylanase from Cellvibrio mixtus, which selectively hydro- 


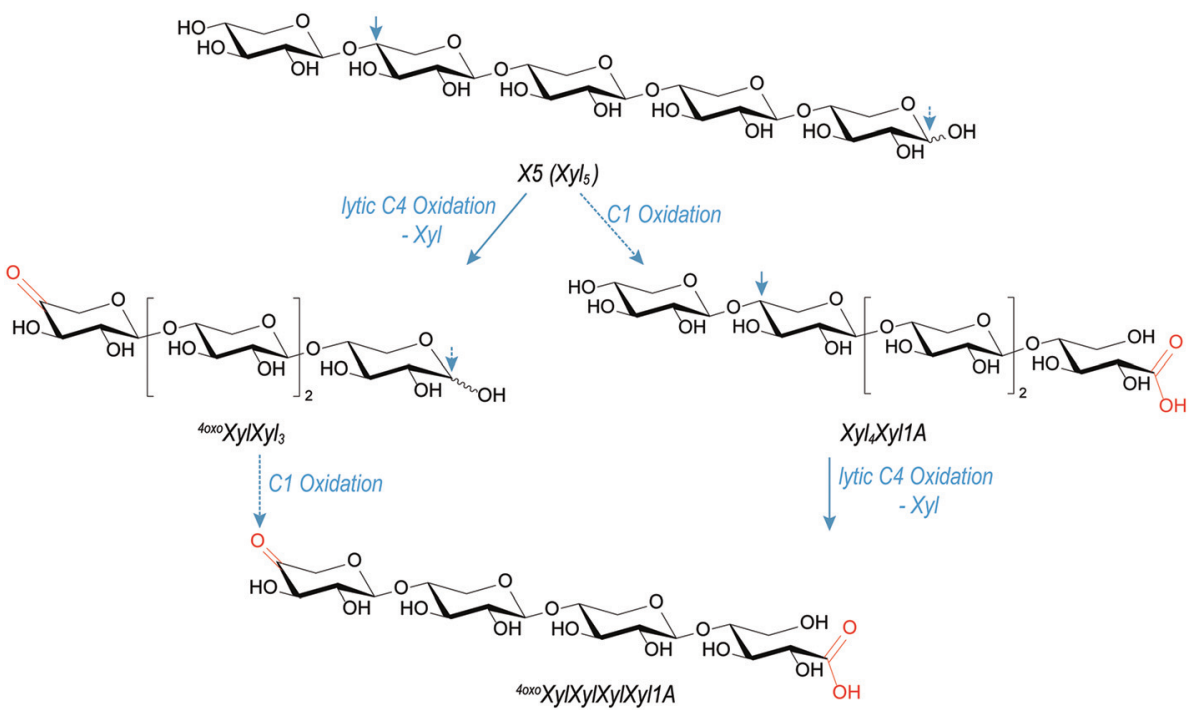

Fig. 5 Suggested likely pathways for the formation of $\mathrm{m} / \mathrm{z} 559.15$ product from Fenton-induced $\mathrm{X} 5$ oxidation through lytic $\mathrm{C} 4$ oxidation ( $\mathrm{HO}$; $\mathrm{O}_{2}$ ) and reducing end $\mathrm{C} 1$ oxidation $\left(\mathrm{H}_{2} \mathrm{O}_{2}\right)$, with loss of the non-reducing end unit, forming ${ }^{40 x}{ }^{\circ} \mathrm{XylXylXylXyl1A}$ as product.

lyzes certain 1,4- $\beta$-glycosidic bonds within the $\beta$-( $1 \rightarrow 4)$-xylan backbone. Consequently, the product profile of oxidized AX derived oligosaccharides was characterized by hydrophilic interaction UPLC-MS ${ }^{2}$. Scheme 1 provides structures, names, and abbreviations of expected $\mathrm{AX}$ oxidation products originating from $\mathrm{HO}^{\circ}$-attack on xylose and arabinose carbons $\mathrm{C} 1-5$ along the arabinoxylan backbone, based on our results from the (A)XOS model system experiments presented above. Reaction shown are categorized as lytic and non-lytic reactions, where lytic reactions cause chain scission within the polysaccharide backbone and hence depolymerization and loss of viscosity. In this study, loss of Ara sidechains is not

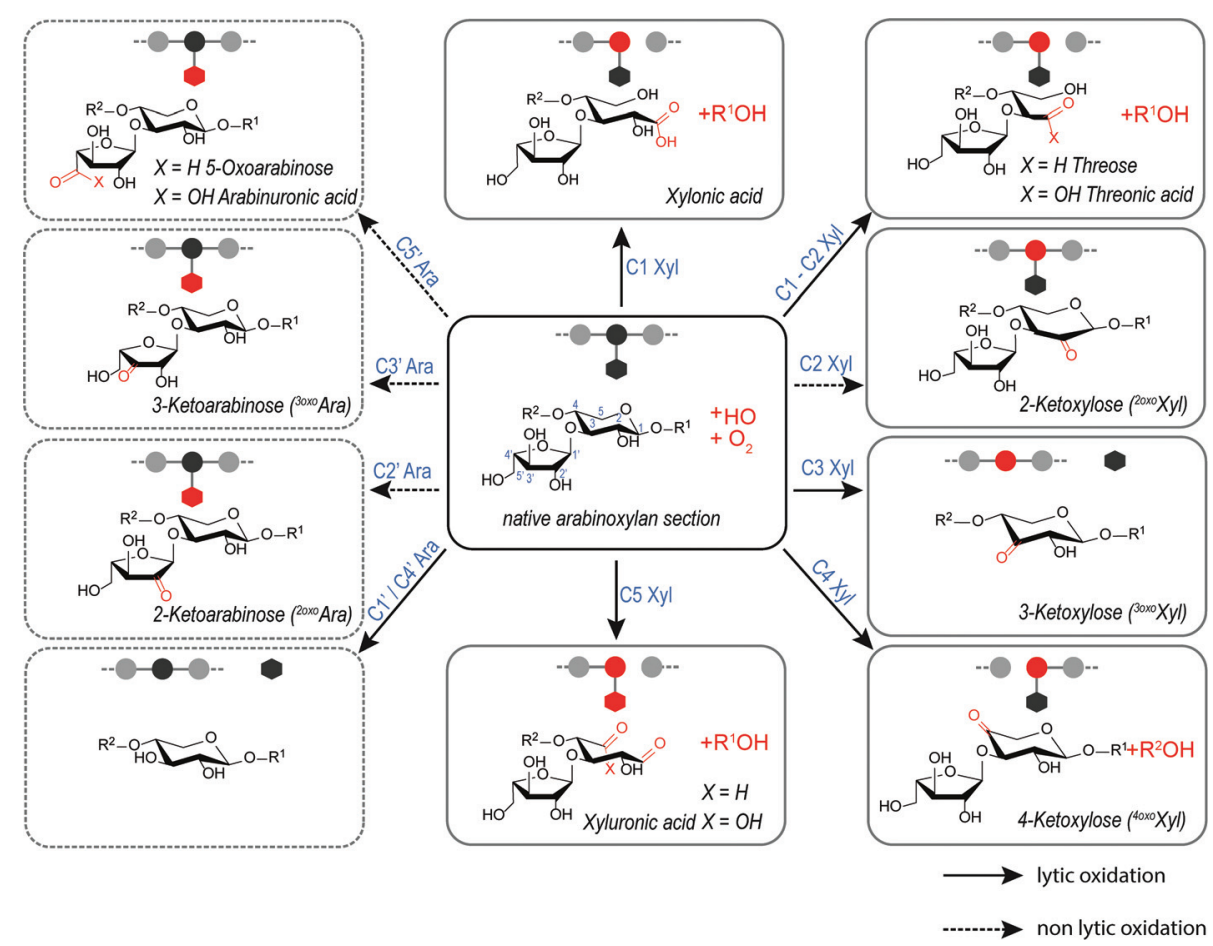

Scheme 1 Overview of expected $\mathrm{AX}$ oxidation products in the presence of molecular oxygen mediated by hydroxyl radicals ( $\mathrm{HO} \mathrm{O}^{\circ}$ ), which attack at any of the five carbons of xylose (plane $\square$ ) and arabinose (hashed i.). Starting from $\alpha-(1 \rightarrow 3)$-linked L-arabinofuranosyl (Araf) that is part of $\beta$-( $1 \rightarrow 4$ )xylan backbone, both lytic (plane arrows), which introduces chain scissions, and non-lytic oxidation (hashed arrows) are shown. Threose can by formed by a lytic cross-ring cleavage (C1-C2). 
classified as lytic, as their loss has a negligible impact on molecular weight and viscosity of the polysaccharide material.

3.3.1. AX polymer oxidation - UPLC analysis with basic eluent. As similarly observed for the Fenton oxidized oligosac- charides above, significant amounts of both acidic and neutral oxidation products were produced by the $\mathrm{HO}^{\bullet}$ induced degradation of arabinoxylan (see Fig. 6). The acidic fraction (F1) in Fig. $6 \mathrm{~B}$ and $\mathrm{C}$ demonstrates that primary oxidation products were dominating, namely $m / z$ 165.04, 297.08, 429.12, 561.17,

(A) Gradient I $\left(0.1 \% \mathrm{NH}_{3}\right) \mathrm{BPI}$ at $24 \mathrm{~h}$ Fenton Oxidation of $\mathrm{AX}$ after enzymatic digestion

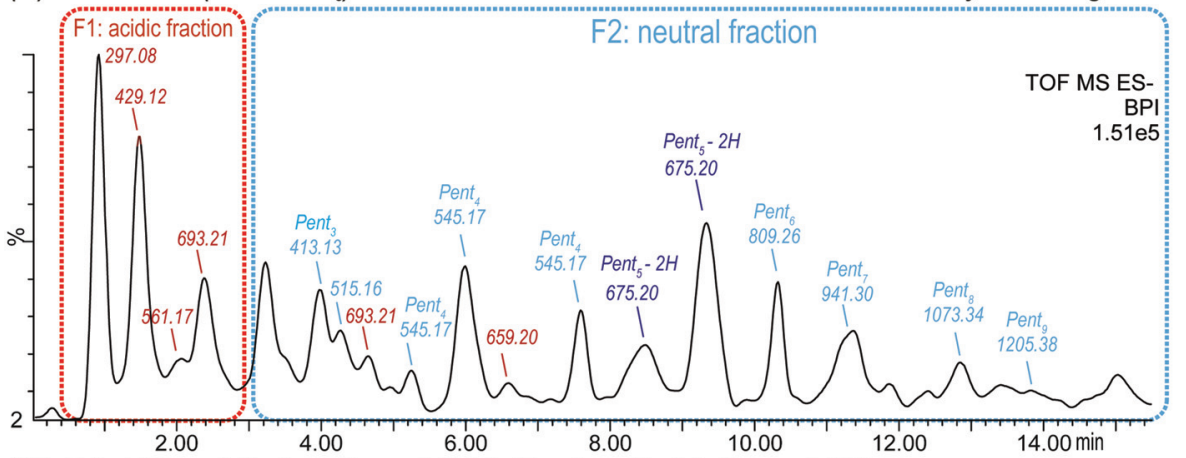

(B) F1: MS acidic fraction at $24 \mathrm{~h}$ Fenton Oxidation of $A X$

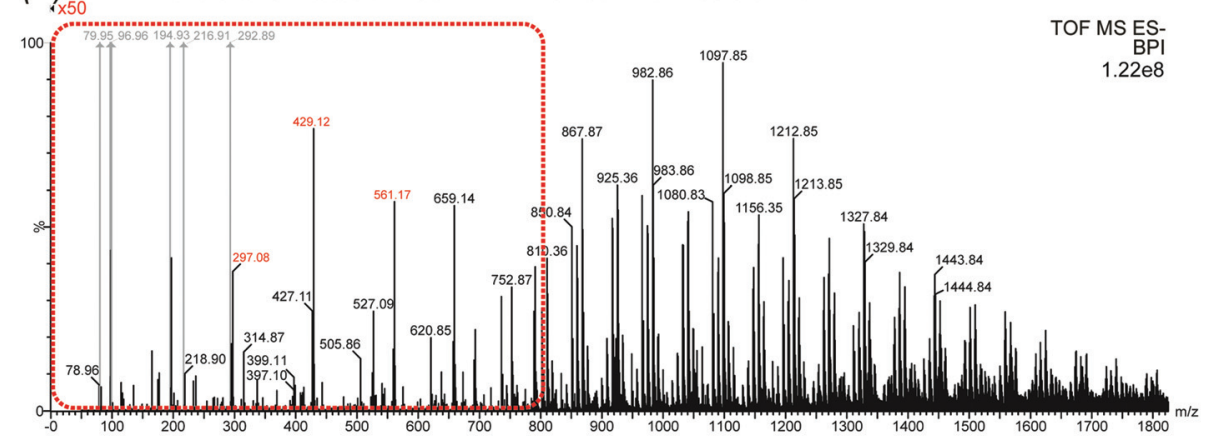

(C) F1: MS acidic fraction at $24 \mathrm{~h}$ Fenton Oxidation of AX-zoom

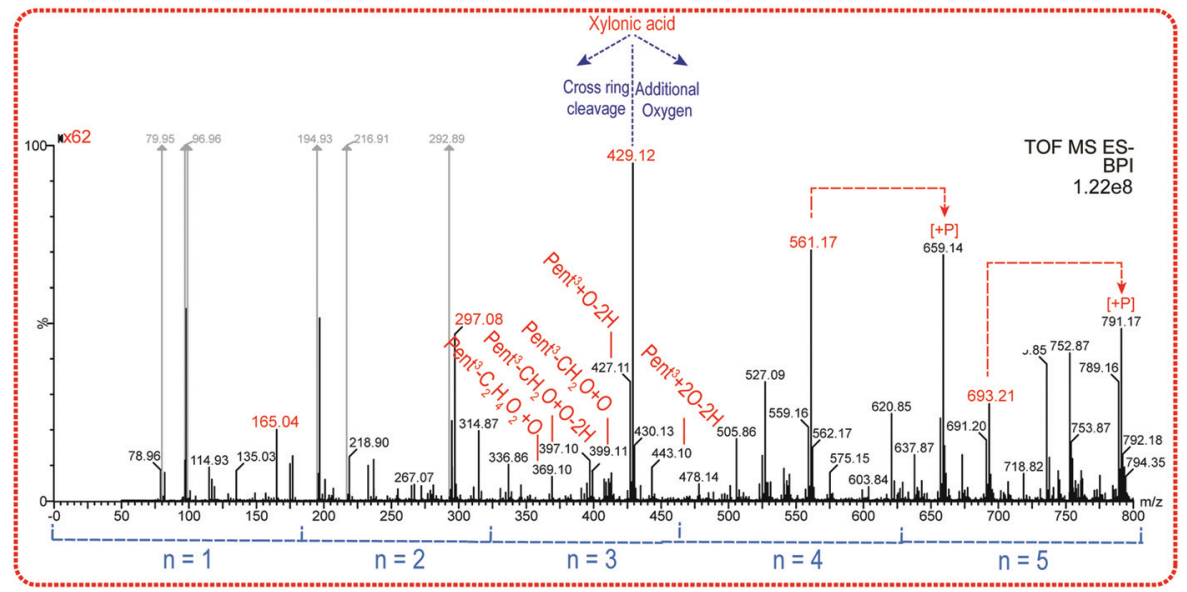

Fig. 6 (A) UPLC-MS base peak chromatogram of released oligosaccharides from $1 \mathrm{mM}$ oxidized wheat arabinoxylan solution oxidized with $100 \mu \mathrm{M}$ $\mathrm{FeSO}_{4}, 100 \mu \mathrm{M}$ ascorbic acid and $50 \mathrm{mM} \mathrm{H}_{2} \mathrm{O}_{2}$ for $24 \mathrm{~h}$ at room temperature. The oxidized AX was digested with endo-1,4- $\beta$-xylanase to obtain diagnostic oligosaccharides suitable in $M_{\mathrm{w}}$ for UPLC-MS ${ }^{2}$ analysis in negative ionization mode using a $\mathrm{BEH}$ Amide column and $\mathrm{ACN} / \mathrm{H}_{2} \mathrm{O}$ gradient $(0.1 \%$ $\mathrm{NH}_{3}$ ). Peaks are labelled with their respective base peak $\mathrm{m} / \mathrm{z}$ and with $n=$ number of monosaccharide units in blue for arabinoxylan oligomers Pent ${ }_{n}$. (B) MS spectrum of acidic products obtained from the highlighted chromatogram region F1 in (A). Signals are labelled with $\mathrm{m} / \mathrm{z}$, and carboxylic acidbearing oligomers are labelled in red. Signals indicated in grey are assigned to common background contamination ions such as buffer salt adducts. (C) MS spectrum of acidic products F1, zoomed in for the range of $\mathrm{m} / \mathrm{z} 50$ to 800 . Carboxylic acid-bearing oligomer are labelled in red, products with additional oxygens and cross-ring cleavages are indicated. Several Xyl + O products, namely $\mathrm{m} / \mathrm{z} 561.17,693.21,825.25,957.29,1089.33$, and 1221.37 were additionally detected as the respective phosphate adduct $(\Delta m=97.96 \mathrm{Da})$ with $\mathrm{m} / \mathrm{z} 659.13,791.17,923.21,1055.25,1187.29$, and 1319.33, respectively (marked with [+P]). 
and $m / z 693.21$ corresponding to $\mathrm{Pent}_{n}+\mathrm{O}$, and hence to xylonic acids Pent ${ }_{(n-1)}$ Xyl1A with $n=1,2,3,4$, and 5 monosaccharide units, respectively. These xylonic acid-bearing oligomers are most likely the result of direct lytic C1-oxidation, although it cannot be excluded that an unknown proportion originates from other lytic action (such as lytic C4-oxidation) that releases an intact reducing end, which then oxidized later due to the high concentration of $\mathrm{H}_{2} \mathrm{O}_{2}$ in solution (50 mM), as observed previously for $\beta$-glucan oxidation under similar Fenton conditions. ${ }^{16}$ The second most abundant signals belong to Pent ${ }_{n}+\mathrm{O}-2 \mathrm{H}$. As discussed earlier on the case of oligosaccharide oxidation, this product class represents lytic C4-oxidation plus secondary C1-oxidation of the reducing end due to the high $\mathrm{H}_{2} \mathrm{O}_{2}$ concentration, (or lytic C1-oxidation plus a carbonyl somewhere from secondary oxidation), vs. simply the C5-oxidation of Ara-side chains to arabinuronic acid (AraA; only 1 oxidative event necessary), or a mixture of both. In contrast to the oligosaccharide oxidation case, where it is unlikely that two independent HO-radical steps are involved, here, with the oxidation of the polysaccharide, the enzymatic sample preparation is responsible for the production of smaller oligosaccharides, making the detection of AraA-bearing oligosaccharides more likely.

In addition, oxidation products carrying carboxylic acid groups at both $\mathrm{C} 1$ + C5 positions along the oligomer could also be detected, as well as the respective acidic cross-ring cleavage products such as tetrose-, glyceric-, and glyconic acidbearing oligomers (e.g. Pent ${ }_{3}-\mathrm{CH}_{2} \mathrm{O}+2 \mathrm{O}-2 \mathrm{H}$ with $\mathrm{m} / z$ 413.09, and threonic acid Pent ${ }_{2}$ Thr1A with $\mathrm{m} / \mathrm{z}$ 399.11) (see Fig. 6 and Table 3).

The neutral fraction (see Fig. 6A) consisted mainly of pentose-oligosaccharides (DP 1 to DP 9), whereas their respective counterparts with one or more oxidized hydroxyl group (oxo-Pent ${ }_{n}$ ) could also be detected, such as oxo-Pent ${ }_{5}$ isomers $(\mathrm{m} / \mathrm{z}$ 675.20) separated using basic gradient I (see Fig. 6A).

3.3.2. Summary of detected and identified products in resolution mode MS. The summary of the detected arabinoxylan derived oxidation products in both gradients using resolution MS mode revealed great similarities to the detected products from oligosaccharide oxidation (see Table 3 ).

The degree of polymerization obtained by the enzymatic digestion was ranging from DP1 to DP13, which was generally higher than the DP of oligosaccharides evaluated as oxidation model compounds in this study. A possible explanation for the limited production of smaller diagnostic (A)XOS by endo-1,4$\beta$-xylanase could be the steric hindrance through side groups. This limitation may be eliminated by the implementation of a selective enzyme mixture, which may simplify the analysis. However, crucial structural information may be lost through a more extensive enzymatic degradation.

Furthermore, it could be observed that the non-selective oxidation of $\mathrm{AX}$ yielded lower product diversity than the oxidation of (A)XOS. This observation indicates that AX polymer was oxidized to a lesser extent than the oligomers. This is in line with the chosen oxidation conditions if the reagent con-
Table 3 Selected Fenton-induced oxidation products of $A X$ in the range of DP1 to DP5 identified by negative ion, resolution UPLC-MS as $\left[\mathrm{M}-\mathrm{H}^{-}\right.$after $24 \mathrm{~h}$ oxidation and xylanase digestion. A BEH Amide column was used in combination with both gradient systems $\left(\mathrm{ACN} / \mathrm{H}_{2} \mathrm{O}\right.$ gradient I with $\mathrm{NH}_{3}$ additive and gradient II with buffered $60 \mathrm{mM}$ ammonium formate eluent system at $\mathrm{pH} 8)^{a}$

\begin{tabular}{|c|c|c|c|c|c|}
\hline$n^{b}$ & 5 & 4 & 3 & 2 & 1 \\
\hline \multicolumn{6}{|l|}{ Neutral products } \\
\hline Pentose $_{n}\left(\right.$ Pent $\left._{n}\right)$ & $677.21^{*}$ & $545.17^{*}$ & $413.13^{*}$ & 281.09 & \\
\hline Pent $_{n}-2 \mathrm{H}$ & $675.20^{*}$ & $543.16^{*}$ & $411.11^{*}$ & 279.07 & \\
\hline $\mathrm{Pent}_{n}-\mathrm{CH}_{2} \mathrm{O}$ & & $515.15^{*}$ & & & \\
\hline \multicolumn{6}{|l|}{ Pent $_{n}-\mathrm{CH}_{2} \mathrm{O}-2 \mathrm{H}$} \\
\hline $\mathrm{Pent}_{n}-\mathrm{C}_{2} \mathrm{H}_{4} \mathrm{O}_{2}$ & 617.19 & 485.15 & & & \\
\hline \multicolumn{6}{|c|}{ Acidic products } \\
\hline \multicolumn{6}{|c|}{ Pentose acid series: xylonic, xylaric, and arabinuronic acid ${ }^{c}$} \\
\hline Pent $_{n}+\mathrm{O}$ & $693.20^{*}$ & $561.16^{*}$ & $429.13^{*}$ & $297.08^{*}$ & 165.04 \\
\hline Pent $_{n}+\mathrm{O}-2 \mathrm{H}$ & $691.19^{*}$ & $559.15^{*}$ & $427.12^{*}$ & 295.07 & 163.03 \\
\hline Pent $_{n}+\mathrm{O}-4 \mathrm{H}$ & 689.17 & 557.13 & 425.09 & 293.05 & \\
\hline \multicolumn{6}{|l|}{ Pent $_{n}+2 \mathrm{O}$} \\
\hline Pent $_{n}+2 \mathrm{O}-2 \mathrm{H}$ & 707.18 & 575.14 & 443.10 & 311.06 & \\
\hline Pent $_{n}+2 \mathrm{O}-4 \mathrm{H}$ & & & 441.09 & 309.05 & \\
\hline
\end{tabular}

Tetrose acid series: onic, uronic, and aric acids ${ }^{c}$ Pent $_{n}-\mathrm{CH}_{2} \mathrm{O}+\mathrm{O}$

Pent ${ }_{2}-\mathrm{CH}_{2} \mathrm{O}+\mathrm{O}-2 \mathrm{H}$

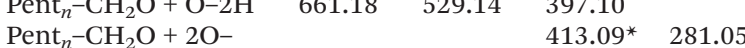

$2 \mathrm{H}$

Glyceric acid series ${ }^{c}$

Pent $_{n}-\mathrm{C}_{2} \mathrm{H}_{4} \mathrm{O}_{2}+2 \mathrm{O}-$

$2 \mathrm{H}$

Pent $_{n}-\mathrm{C}_{2} \mathrm{H}_{4} \mathrm{O}_{2}+3 \mathrm{O}-$

$4 \mathrm{H}$

Glyconic acid series ${ }^{c}$

Pent $_{n}-\mathrm{C}_{3} \mathrm{H}_{6} \mathrm{O}_{3}+\mathrm{O}$

Pent $_{n}-\mathrm{C}_{3} \mathrm{H}_{6} \mathrm{O}_{3}+\mathrm{O}-$

$2 \mathrm{H}$

Pent $_{n}-\mathrm{C}_{3} \mathrm{H}_{6} \mathrm{O}_{3}+2 \mathrm{O}-\quad 617.17 \quad 485.13$

$2 \mathrm{H}$

${ }^{a}$ Experimental values of $\mathrm{m} / \mathrm{z}$ (all within $\pm 2 \mathrm{mDa}$ of theoretical values) with distinct peaks or $\geq 5 \%$ intensity relative to the base peak of the respective fraction (neutral: $\mathrm{m} / \mathrm{z}$ 663.199; acidic: $\mathrm{m} / \mathrm{z}$ 193.035). An asterisk denotes products with $\geq 20 \%$ relative signal intensity. ${ }^{b}$ Indicates the number of total sugar units. ${ }^{c}$ The names of the monosaccharides are given according to the oxidized unit of the oligosaccharides.

centrations are compared relative to the monomer units ( $\mathrm{AX}$ : $150 \mathrm{mM}$ monomers vs. $50 \mathrm{mM} \mathrm{H}_{2} \mathrm{O}_{2}$; (A)XOS: $5 \mathrm{mM}$ monomers vs. $10 \mathrm{mM} \mathrm{H}_{2} \mathrm{O}_{2}$ ). Further oxidation of the $\mathrm{AX}$ material might have also produced a similar diversity of products as the (A)XOS.

The assembled data suggest that resolution HILIC-MS ${ }^{2}$ is a powerful technique for the rapid and precise structural identification of neutral and acidic oligomers derived from arabinoxylan oxidation. Nevertheless, for the complete characterization of the product profile of hydroxyl radical-induced degradation, both gradients presented in this paper need to be applied as was the case in the study for $\beta$-glucan oxidation. ${ }^{16,21}$

\section{Conclusion \& outlook}

A complementary analytical approach using hydrophilic interaction UPLC-MS ${ }^{2}$ in negative ion mode and a combination of 
two gradient systems enabled the investigation of oxidized (A) XOS formed through selective TEMPO-mediated oxidation and non-selective Fenton-induced degradation.

Overall, our method application on branched heterooligosaccharides broadens the application field of the established method enabling the comprehensive characterization of functionalized branched heterooligo- and heteropolysaccharides. The in-depth analysis of acidic oxidation products synthesized by TEMPO-mediated oxidation provides mechanistic insights in the selective functionalization of oligosaccharides and polysaccharides. The chosen $\mathrm{MS}^{2}$ condition allowed for the differentiation and linkage assignment of constitutionally isomeric native and synthesized C1-oxidation products. The implementation of higher collision energies facilitated the structural elucidation of stable C1-oxidized (A)XOS. Moreover, the localization of newly introduced functional groups by $\mathrm{MS}^{2}$ could be shown on the example of a lytic $\mathrm{C} 4$ oxidation combined with reducing end oxidation. This analytical investigation enables the detailed elucidation of reaction pathways occurring during polysaccharide functionalizations such as Fenton oxidation. The implemented enzymatic sample preparation strategy revealed appropriate size distribution and improved signal strength in the HILIC-MS ${ }^{2}$ analysis enabling the comprehensive characterization of Fenton-induced arabinoxylan oxidation In further findings, MS resolution mode was sufficient for the separation of near isobaric products $(\Delta m=\sim 0.05 \mathrm{Da})$. This feature prevents misassigning oxidation products due to a lack of resolution. In general, the complementary basic and buffer gradient systems yielded appropriate chromatographic resolution in combination with qTOF MS detection. However, to characterize the complex product mixture of hydroxyl radicalinduced degradation, both gradients need to be considered. While gradient I enables the characterization of neutral products, gradient II is crucial to investigate acidic products and their isomeric species.

The analytical approach presented enables a molecular screening of selective and non-selective polysaccharide modifications providing valuable mechanistic insight within the broad field of polysaccharide applications.

\section{Abbreviations}

$\begin{array}{ll}\text { AX } & \text { Arabinoxylan } \\ \text { AXOS } & \text { Arabinoxylan oligosaccharides } \\ \text { (A)XOS } & \text { Xylo- and arabinoxylan oligosaccharides } \\ \text { DP } & \text { Degree of polymerization } \\ \text { HO } & \text { Hydroxyl radicals } \\ \text { TEMPO } & \text { 2,2,6,6-Tetramethylpiperidine 1-oxyl } \\ \text { XOS } & \text { Xylooligosaccharides }\end{array}$

\section{Funding source}

The study was funded by ETH Zurich and did not receive any specific grant from funding agencies in the public, commercial, or not-for-profit sectors.

\section{Conflicts of interest}

There are no conflicts to declare.

\section{Acknowledgements}

The authors gratefully thank Dr Guido Zeegers for his scientific support in the LC-MS operation, and Jasmin Hirt for the synthesis of oxidized (A)XOS.

\section{References}

1 M. Mendis and S. Simsek, Food Hydrocolloids, 2014, 42, 239-243.

2 J. Liu, S. Willför and C. Xu, Bioact. Carbohydr. Diet. Fibre, 2015, 5, 31-61.

3 A. Kiszonas, E. Fuerst and C. Morris, Cereal Chem., 2013, 90, 387-395.

4 M. R. Cyran, Processing and Impact on Active Components in Food, 2015, 319-328, DOI: 10.1016/b978-0-12-4046993.00038-x.

5 T. Demuth, J. Betschart and L. Nyström, Carbohydr. Polym., 2020, 240, 116328.

6 M. S. Izydorczyk, Arabinoxylans, in Handbook of hydrocolloids, Woodhead Publishing, 2009, pp. 653-692.

7 A. Bagdi, S. Tömösközi and L. Nyström, Carbohydr. Polym., 2016, 152, 263-270.

8 R. Kivelä, U. Henniges, T. Sontag-Strohm and A. Potthast, Carbohydr. Polym., 2012, 87, 589-597.

9 M. N. Schuchmann and C. Von Sonntag, Int. J. Radiat. Biol., 1977, 34, 397-400.

10 R. Kivelä, T. Sontag-Strohm, J. Loponen, P. Tuomainen and L. Nyström, Carbohydr. Polym., 2011, 85, 645-652.

11 L. Saulnier, P.-E. Sado, G. Branlard, G. Charmet and F. Guillon, J. Cereal Sci., 2007, 46, 261-281.

12 A. M. Faure, M. L. Andersen and L. Nyström, Carbohydr. Polym., 2012, 87, 2160-2168.

13 R. Kivelä, F. Gates and T. Sontag-Strohm, J. Cereal Sci., 2009, 49, 1-3.

14 Y. J. Wang, N. Mäkelä, N. H. Maina, A. M. Lampi and T. Sontag-Strohm, Food Chem., 2016, 197(Pt B), 1324-1330.

15 A. Potthast, J. Röhrling, T. Rosenau, A. Borgards, H. Sixta and P. Kosma, Biomacromolecules, 2003, 4, 743-749.

16 S. Boulos and L. Nyström, Front. Chem., 2017, 5, 90.

17 M. Juvonen, M. Kotiranta, J. Jokela, P. Tuomainen and M. Tenkanen, Food Chem., 2019, 275, 176-185.

18 O. Hernandez-Hernandez, I. Calvillo, R. Lebron-Aguilar, F. J. Moreno and M. L. Sanz, J. Chromatogr., A, 2012, 1220, 57-67.

19 B. Westereng, M. O. Arntzen, F. L. Aachmann, A. Varnai, V. G. Eijsink and J. W. Agger, J. Chromatogr., A, 2016, 1445, 46-54. 
20 A. S. Moreira, E. V. da Costa, D. V. Evtuguin, M. A. Coimbra, F. M. Nunes and M. R. Domingues, J. Mass Spectrom., 2014, 49, 280-290.

21 S. Boulos and L. Nyström, Analyst, 2016, 141, 6533-6548.

22 K. Hashimoto, S. I. Imanishi, M. Okada and H. Sumitomo, J. Polym. Sci., Part A: Polym. Chem., 1991, 29, 1271-1279.

23 N. Tamura, M. Hirota, T. Saito and A. Isogai, Carbohydr. Polym., 2010, 81, 592-598.

24 A. Bagdi, S. Tömösközi and L. Nyström, Food Hydrocolloids, 2017, 63, 219-225.

25 B. Westereng, J. W. Agger, S. J. Horn, G. Vaaje-Kolstad, F. L. Aachmann, Y. H. Stenstrom and V. G. Eijsink, J. Chromatogr., A, 2013, 1271, 144-152.
26 J. Hao, J. Lu, N. Xu, R. J. Linhardt and Z. Zhang, Carbohydr. Polym., 2016, 146, 238-244.

27 A. E. De Nooy, A. C. Besemer and H. van Bekkum, Synthesis, 1996, 1153-1176.

28 B. Domon and C. E. Costello, Glycoconjugate J., 1988, 5, 397-409.

29 A. G. Leijdekkers, M. G. Sanders, H. A. Schols and H. Gruppen, J. Chromatogr., A, 2011, 1218, 92279235.

30 J. Simoes, A. S. Moreira, E. da Costa, D. Evtyugin, P. Domingues, F. M. Nunes, M. A. Coimbra and M. R. Domingues, Carbohydr. Polym., 2016, 148, 290299. 